\title{
Can a 'state of the art' chemistry transport model simulate Amazonian tropospheric chemistry?
}

\section{Citation}

Barkley, Michael P., Paul I. Palmer, Laurens Ganzeveld, Almut Arneth, Daniel Hagberg, Thomas Karl, Alex Guenther, et al. 2011. "Can a 'state of the Art' Chemistry Transport Model Simulate Amazonian Tropospheric Chemistry?" Journal of Geophysical Research 116 (D16). https:// doi.org/10.1029/2011jd015893.

\section{Permanent link}

http://nrs.harvard.edu/urn-3:HUL.InstRepos:41461231

\section{Terms of Use}

This article was downloaded from Harvard University's DASH repository, and is made available under the terms and conditions applicable to Other Posted Material, as set forth at http:// nrs.harvard.edu/urn-3:HUL.InstRepos:dash.current.terms-of-use\#LAA

\section{Share Your Story}

The Harvard community has made this article openly available.

Please share how this access benefits you. Submit a story.

Accessibility 


\title{
Can a "state of the art" chemistry transport model simulate Amazonian tropospheric chemistry?
}

\author{
Michael P. Barkley, ${ }^{1}$ Paul I. Palmer, ${ }^{2}$ Laurens Ganzeveld, ${ }^{3}$ Almut Arneth, ${ }^{4,5}$ \\ Daniel Hagberg, ${ }^{4}$ Thomas Karl, ${ }^{6}$ Alex Guenther, ${ }^{6}$ Fabien Paulot, ${ }^{7}$ Paul O. Wennberg, ${ }^{7,8}$ \\ Jingqiu Mao, ${ }^{9}$ Thomas P. Kurosu, ${ }^{10}$ Kelly Chance, ${ }^{10}$ J.-F. Müller, ${ }^{11}$ Isabelle De Smedt, ${ }^{11}$ \\ Michel Van Roozendael, ${ }^{11}$ Dan Chen, ${ }^{12,13}$ Yuxuan Wang, ${ }^{14}$ and Robert M. Yantosca ${ }^{15}$
}

Received 2 March 2011; revised 8 April 2011; accepted 10 May 2011; published 17 August 2011.

[1] We present an evaluation of a nested high-resolution Goddard Earth Observing System (GEOS)-Chem chemistry transport model simulation of tropospheric chemistry over tropical South America. The model has been constrained with two isoprene emission inventories: (1) the canopy-scale Model of Emissions of Gases and Aerosols from Nature (MEGAN) and (2) a leaf-scale algorithm coupled to the Lund-Potsdam-Jena General Ecosystem Simulator (LPJ-GUESS) dynamic vegetation model, and the model has been run using two different chemical mechanisms that contain alternative treatments of

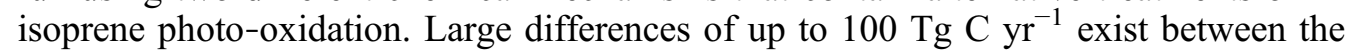
isoprene emissions predicted by each inventory, with MEGAN emissions generally higher. Based on our simulations we estimate that tropical South America $\left(30-85^{\circ} \mathrm{W}, 14^{\circ} \mathrm{N}-25^{\circ} \mathrm{S}\right)$ contributes about $15-35 \%$ of total global isoprene emissions. We have quantified the model sensitivity to changes in isoprene emissions, chemistry, boundary layer mixing, and soil $\mathrm{NO}_{\mathrm{x}}$ emissions using ground-based and airborne observations. We find GEOS-Chem has difficulty reproducing several observed chemical species; typically hydroxyl concentrations are underestimated, whilst mixing ratios of isoprene and its oxidation products are overestimated. The magnitude of model formaldehyde ( $\mathrm{HCHO})$ columns are most sensitive to the choice of chemical mechanism and isoprene emission inventory.

We find GEOS-Chem exhibits a significant positive bias (10-100\%) when compared with HCHO columns from the Scanning Imaging Absorption Spectrometer for Atmospheric Chartography (SCIAMACHY) and Ozone Monitoring Instrument (OMI) for the study year 2006. Simulations that use the more detailed chemical mechanism and/or lowest isoprene emissions provide the best agreement to the satellite data, since they result in lower-HCHO columns.

Citation: Barkley, M. P., et al. (2011), Can a "state of the art" chemistry transport model simulate Amazonian tropospheric chemistry?, J. Geophys. Res., 116, D16302, doi:10.1029/2011JD015893.

\section{Introduction}

[2] The Amazon Basin, covering nearly 6 million square kilometers and containing the world's largest rainforest, is

\footnotetext{
${ }^{1}$ EOS Group, Department of Physics and Astronomy, University of Leicester, Leicester, UK.

${ }^{2}$ School of GeoSciences, University of Edinburgh, Edinburgh, UK.

${ }^{3}$ Earth System Sciences, Department of Environmental Sciences, Wageningen University and Research Center, Wageningen, Netherlands.

${ }^{4}$ Department of Physical Geography and Ecosystems Analysis, Geobiosphere Science Center, Lund University, Lund, Sweden.

${ }^{5}$ Atmospheric Environmental Research, Institute of Meteorology and Climate Research, Karlsruhe Institute of Technology, Karlsruhe, Germany.

${ }^{6}$ National Center of Atmospheric Research, Boulder, Colorado, USA.

${ }^{7}$ Division of Engineering and Applied Science, California Institute of Technology, Pasadena, California, USA.
}

Copyright 2011 by the American Geophysical Union. 0148-0227/11/2011JD015893 the most productive and diverse ecosystem on Earth. One of the reasons why the Amazon rainforest is important to climate is because tropical vegetation emit a wide range of highly reactive nonmethane biogenic volatile organic compounds

\footnotetext{
${ }^{8}$ Division of Geological and Planetary Sciences, California Institute of Technology, Pasadena, California, USA.

${ }^{9}$ Geophysical Fluid Dynamics Laboratory, Princeton University, Princeton, New Jersey, USA.

${ }^{10}$ Atomic and Molecular Physics Division, Harvard-Smithsonian Center for Astrophysics, Cambridge, Massachusetts, USA.

${ }^{11}$ Belgian Institute for Space Aeronomy, Brussels, Belgium.

${ }^{12}$ Department of Environmental Science and Engineering, Tsinghua University, Beijing, China.

${ }^{13}$ Now at Department of Atmospheric and Oceanic Sciences, University of California, Los Angeles, California, USA.

${ }^{14}$ Ministry of Education Key Laboratory for Earth System Modeling, Center for Earth System Science, Institute for Global Change Studies, Tsinghua University, Beijing, China.

${ }^{15}$ Division of Engineering and Applied Sciences, Harvard University, Cambridge, Massachusetts, USA.
} 
(BVOCs) into the atmosphere. These BVOCs play a critical role in global atmospheric chemistry and climate as their photochemical reactions influence the oxidation capacity of the atmosphere [Poisson et al., 2000; Monson and Holland, 2001], and the lifetimes and distributions of other key trace gases, such as carbon monoxide $(\mathrm{CO})$ and methane $\left(\mathrm{CH}_{4}\right)$ [Granier et al., 2000; Collins et al., 2002]. The most important BVOC emitted by vegetation is isoprene since it accounts for about half of the total global BVOC budget [Guenther, 2002], and because of its influence on tropospheric ozone [Jenkin and Clemitshaw, 2000; Sanderson et al., 2003; Fiore et al., 2005] and its precursor role in the formation of secondary organic aerosol [Claeys et al., 2004; Kanakidou et al., 2005]. Isoprene emissions are also relevant to carbon cycle studies as they represent a loss of fixed carbon from the terrestrial biosphere [Kesselmeier et al., 2002] and a nonnegligible photochemical source of carbon dioxide [Folberth et al., 2005].

[3] Despite the Amazon Basin being acknowledged as a significant isoprene source [Guenther et al., 2006; Arneth et al., 2008], there have only been a few measurement campaigns to date that have targeted this region (owing in part to inaccessibility), resulting in a limited number of in situ measurements. Leaf and branch level measurements [Kuhn et al., 2002] offer insight to small-scale processes, whilst tower, balloon and airborne platforms provide information on localized emissions [e.g., Helmig et al., 1998; Karl et al., 2007; Kuhn et al., 2007]. However, for the Amazon Basin as a whole, isoprene emissions are poorly quantified. Bottomup emissions inventories, such as the widely used Model of Emissions of Gases and Aerosols from Nature (MEGAN) [Guenther et al., 2006], are highly uncertain as they rely on upscaling sparse point measurements to landscape scales; where ecosystem diversity is high, as in tropical ecosystems, this is especially difficult. Moreover, the empirical algorithms that drive variations in the bottom-up emissions are mostly based on studies of extratropical plant species, which may not be applicable to tropical vegetation. Model studies conducted at relatively coarse spatial scales have generally been unable to accurately reproduce the sparse observations of Amazonian isoprene fluxes and surface concentrations without some form of adjustment or scaling of the bottom-up emissions [von Kuhlmann et al., 2004; Jöckel et al., 2006; Müller et al., 2008; Barkley et al., 2008].

[4] Formaldehyde (HCHO), a short-lived trace gas and high yield product of isoprene oxidation, can provide additional information on surface isoprene emissions on length scales of order $100 \mathrm{~km}$ [Palmer et al., 2003]. However, since $\mathrm{HCHO}$ originates from a variety of atmospheric and surface sources, careful disaggregation is needed to accurately derive satellite-based (i.e., top-down) isoprene emission estimates. Globally, the largest source of HCHO is produced from the oxidation of methane [Stavrakou et al., 2009a], though this only maintains ambient background concentrations, such as found in the remote marine atmosphere. Over land, BVOC oxidation over densely vegetated areas and anthropogenic VOC oxidation over urban areas create strong regional $\mathrm{HCHO}$ enhancements, easily observed from space. Biomass burning and wild fires are also significant localized $\mathrm{HCHO}$ sources, owing to directly released $\mathrm{HCHO}$ during incomplete combustion and from the oxidation of coemitted VOCs [Andreae and Merlet, 2001].
[5] During the last decade satellite observations of $\mathrm{HCHO}$ columns, retrieved using ultraviolet (UV) absorption spectroscopy [Chance et al., 2000; De Smedt et al., 2008], have been used in several studies to map top-down isoprene emissions on continental and global scales [see, e.g., Palmer et al., 2003, 2006; Shim et al., 2005; Fu et al., 2007; Millet et al., 2007; Barkley et al., 2008; Stavrakou et al., 2009b]. Recent work by Barkley et al. [2008], using HCHO column data from the Global Ozone Monitoring Experiment (GOME) [European Space Agency, 1995; Burrows et al., 1999] and Scanning Imaging Absorption Spectrometer for Atmospheric Chartography (SCIAMACHY) [Bovensmann et al., 1999] instruments, identified potentially large gaps in our quantitative understanding of Amazonian isoprene emissions, and unexplained observed seasonal variations [Barkley et al., 2009]. In contrast, SCIAMACHY top-down estimates derived by Stavrakou et al. [2009b] gave better agreement with the MEGAN inventory for the Amazon region; in that study emissions were calculated using the Model for Hydrocarbon Emissions by the Canopy (MOHYCAN) [Müller et al., 2008] forced with European Center for Medium-Range Weather Forecast (ECMWF) meteorological analyses. These differences, in part, reflect the difficulties and uncertainties associated with inferring isoprene emissions from satellite measurements of HCHO columns. Critically, the accuracy of the top-down emissions largely depends on the ability of the chosen chemistry transport model (CTM), the intermediary used to invert the retrieved $\mathrm{HCHO}$ columns, to accurately simulate the chemistry and dynamics of the rainforest atmosphere. Model spatial resolution is important in this respect, both to capture localized dynamical and chemical processes, and distinguish biogenic and pyrogenic contributions to the observed HCHO columns [Barkley et al., 2008].

[6] However, modeling Amazonian tropospheric chemistry is difficult [Ganzeveld et al., 2002; von Kuhlmann et al., 2004; Butler et al., 2008]. Besides the large uncertainties associated with the bottom-up BVOC emissions (typically $>100 \%$ ), the subsequent oxidation chemistry occurring in the prevalent low- $\mathrm{NO}_{\mathrm{x}}$ conditions is poorly understood and often inadequately parameterized. In particular, there has been much emphasis placed on the underestimation of hydroxyl $(\mathrm{OH})$ concentrations over dense tropical rainforests by most CTMs and chemistry-climate models [e.g., Butler et al., 2008]. Various plausible mechanisms to recycle or regenerate $\mathrm{OH}$ through improved isoprene degradation schemes have been proposed and compared with observational data [Butler et al., 2008; Lelieveld et al., 2008; Paulot et al., 2009a; Stavrakou et al., 2010]. Given the large uncertainties of these chemical mechanisms much remains unresolved. Although significant effort has gone into improving our understanding of tropical oxidation chemistry, the influence of physical and micrometeorological processes on reactive gas exchange can be equally, if not more, important [Pike et al., 2010; Pugh et al., 2010]. Correct parameterizations of both in-canopy (e.g., soil $\mathrm{NO}_{\mathrm{x}}$ emissions, deposition) and above-canopy (e.g., convection, turbulent mixing, segregation effects) processes are essential to properly model the tropical atmosphere [Ganzeveld and Lelieveld, 2004; Karl et al., 2004; Ganzeveld et al., 2008; Pugh et al., 2010].

[7] In this manuscript we present the first comprehensive evaluation of a high-resolution simulation of tropospheric chemistry over tropical South America, performed by a 


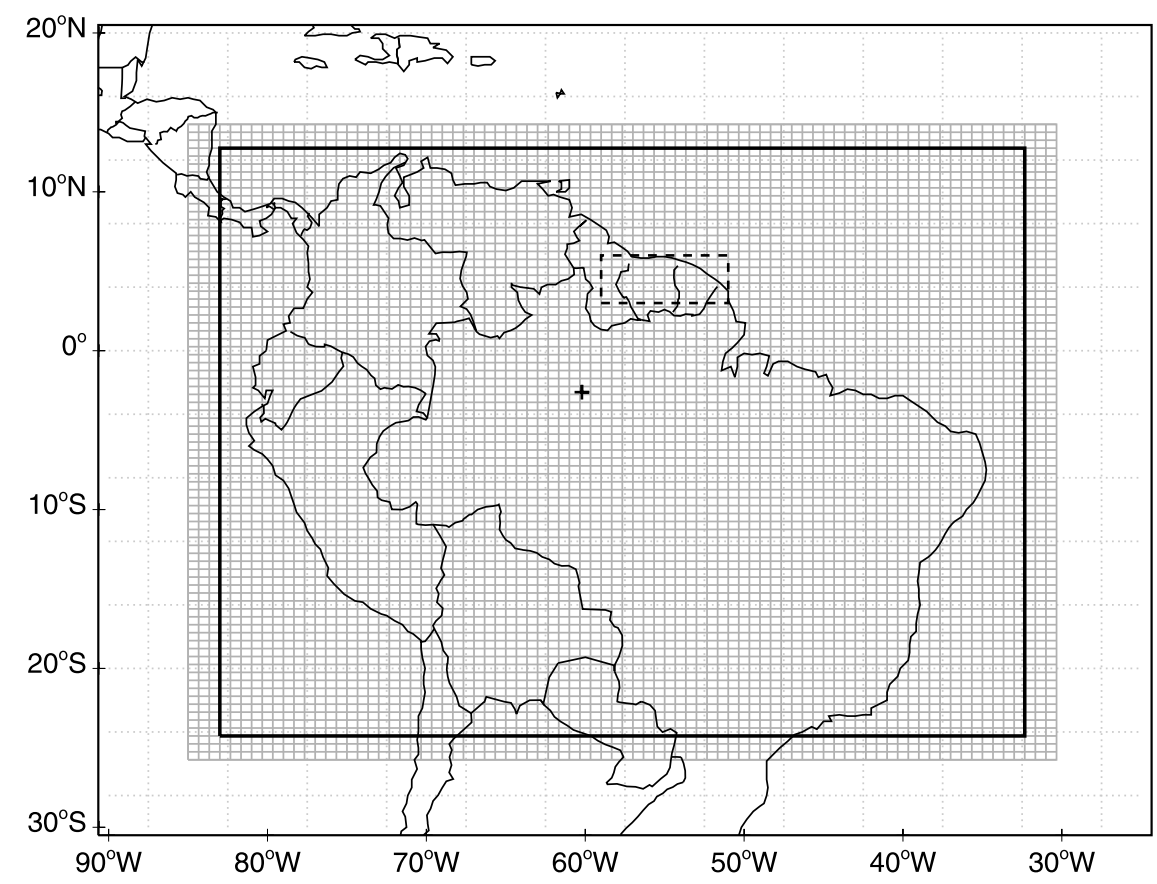

Figure 1. Schematic showing the domain of the Amazon nested grid. The thick black line is the actual boundary of the nested window; $0.5^{\circ} \times 0.667^{\circ}$ grid cells outside the black line represents the buffer zone for the boundary conditions. The GEOS-Chem $4^{\circ} \times 5^{\circ}$ horizontal grid is shown by the dotted light grey lines. The location of the TROFFEE campaign [Karl et al., 2007] is shown as the black cross (see section 4.1). The domain of the GABRIEL campaign [Stickler et al., 2007] is shown inset by the black dashed line (see section 4.2).

nested grid version of the widely used Goddard Earth Observing System (GEOS)-Chem CTM [Bey et al., 2001]. Given that in future work we want to use GEOS-Chem to derive top-down isoprene emissions for this region, and knowing the large uncertainties associated with simulating Amazonian BVOC emissions and tropospheric chemistry, the objective of this paper is two fold. First, we assess the ability of GEOS-Chem to accurately simulate isoprene oxidation chemistry and other observed key atmospheric constituents over the Amazon rainforest. Secondly, we evaluate the model's usefulness to interpret satellite observations of $\mathrm{HCHO}$, or in other words, its suitability for inferring topdown isoprene emission estimates. To achieve these objectives we limit our focus on the model sensitivity to four key processes: surface BVOC emissions, chemistry, boundary layer mixing, and soil $\mathrm{NO}_{\mathrm{x}}$ emissions. To determine the relative importance of each process we use surface and airborne observations from previous Amazon field campaigns, along with satellite observations of $\mathrm{HCHO}$ vertical columns, to validate the model output. This work is novel in that for the first time GEOS-Chem will be forced with two contrasting BVOC emission inventories to assess their influence on Amazonian tropospheric chemistry.

[8] This manuscript is structured as follows. In section 2 we provide an overview of the GEOS-Chem model and outline the chemical mechanism. We discuss and compare the two BVOC emission inventories separately in section 3. In section 4 we evaluate the model using the surface/ airborne field measurements and the satellite HCHO column data; details of the satellite $\mathrm{HCHO}$ retrievals are provided in the auxiliary material. ${ }^{1}$ We discuss the potential implications resulting from the model validation in section 5 , and conclude the paper in section 6 .

\section{GEOS-Chem}

\subsection{Overview}

[9] GEOS-Chem is a global 3-D chemistry transport model [Bey et al., 2001] which we use here to simulate tropospheric chemistry over tropical South America. To reproduce the trace gas distributions over Amazon rainforest at relatively fine spatial scales we run GEOS-Chem (v8-03-01) in a oneway high-resolution nested grid mode. This nested grid capability of GEOS-Chem was first developed to study the east Asia region by Wang et al. [2004], and was more recently updated by Chen et al. [2009]. Here we adapt the model to be centered over the Amazon Basin, as shown in Figure 1. The model has a horizontal resolution of $0.667^{\circ} \times$ $0.5^{\circ}$ (longitude $\times$ latitude) which is consistent with the forcing meteorology taken from the Goddard Earth Observing System (GEOS-5) of the NASA Global Modeling and Assimilation Office (GMAO) [Rienecker et al., 2008]. The GEOS-5 meteorological data are updated every $6 \mathrm{~h}$ for 3-D variables and every $3 \mathrm{~h}$ for surface fields and mixing depths. In the vertical coordinate, we run the model with 47 hybrid eta levels extending from the surface to $0.01 \mathrm{hPa}$, with the boundary layer up to $2 \mathrm{~km}$ resolved by 14 layers (with

\footnotetext{
${ }^{1}$ Auxiliary materials are available in the HTML. doi:10.1029/ 2011 JD015893.
} 
Table 1. GEOS-Chem Anthropogenic, Biofuels, and Selected Biomass Burning Emissions From the Amazon for $2006^{\mathrm{a}}$

\begin{tabular}{lcccc}
\hline \multicolumn{1}{c}{ Species $^{\mathrm{b}}$} & Units & Anthropogenic & Biofuels & $\begin{array}{c}\text { Biomass } \\
\text { Burning }\end{array}$ \\
\hline $\mathrm{CO}$ & $\mathrm{Tg}$ & 15.70 & 15.53 & 50.85 \\
$\mathrm{NO}_{\mathrm{x}}$ & $\mathrm{Tg} \mathrm{N}$ & 1.01 & 0.16 & 0.49 \\
Acetone & $\mathrm{Tg} \mathrm{C}$ & 0.04 & 0.03 & 0.22 \\
Acetaldehyde & $\mathrm{Tg} \mathrm{C}$ & - & 0.06 & 0.22 \\
$\mathrm{ALK} 4$ & $\mathrm{Tg} \mathrm{C}$ & 1.52 & 0.05 & 0.09 \\
$\mathrm{C}_{2} \mathrm{H}_{6}$ & $\mathrm{Tg} \mathrm{C}$ & 0.18 & 0.14 & 0.41 \\
$\mathrm{C}_{3} \mathrm{H}_{6}$ & $\mathrm{Tg} \mathrm{C}$ & 0.74 & 0.39 & 0.49 \\
$\mathrm{C}_{3} \mathrm{H}_{8}$ & $\mathrm{Tg} \mathrm{C}$ & 0.28 & 0.06 & 0.34 \\
$\mathrm{HCHO}$ & $\mathrm{Tg}$ & - & 0.13 & 0.52 \\
$\mathrm{MEK}^{\mathrm{SO}}$ & $\mathrm{Tg} \mathrm{C}$ & 0.05 & 0.11 & 0.15 \\
$\mathrm{NH}_{3}$ & $\mathrm{Tg} \mathrm{S}$ & - & - & 0.27 \\
$\mathrm{BC}^{\mathrm{OC}}$ & $\mathrm{Tg} \mathrm{NH}$ & - & - & 0.68 \\
& $\mathrm{Tg}$ & - & - & 0.32 \\
& $\mathrm{Tg}$ & - & - & 2.53 \\
\hline
\end{tabular}

${ }^{\mathrm{a}} \mathrm{NO}_{\mathrm{x}}$ emissions from soils, fertilizers, and lightning are $0.91,0.03$, and $0.83 \mathrm{Tg} \mathrm{N}$, respectively.

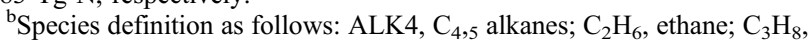
propane; MEK, $>\mathrm{C}_{3}$ ketones; $\mathrm{C}_{3} \mathrm{H}_{6}$, propene; $\mathrm{BC}$, black carbon; $\mathrm{OC}$, organic carbon.

midpoints at approximately 70, 200, 330, 470, 600, 740, $880,1000,1160,1300,1440 \mathrm{~m}$ altitude for a column based at sea level).

[10] Tracers are transported using a semi-Lagrangian approach for advection [Lin and Rood, 1996] and a relaxed Arakawa-Schubert (RAS) scheme for moist convection [Moorthi and Suarez, 1992]. Two options are available for the vertical mixing of chemical tracers within the planetary boundary layer (PBL): (1) a full-mixing scheme which ensures emissions and mixing ratios are constant with altitude at each chemistry time step (60 mins) and (2) a nonlocal scheme that can include "local" mixing between adjacent layers and, depending on the stability of the PBL, "nonlocal" mixing due to turbulent eddies. The nonlocal scheme is based on the formulation of Holtslag and Boville [1993] and was implemented into GEOS-Chem by Lin and McElroy [2010]; in their study it yielded a more realistic simulation of $\mathrm{NO}_{2}$ and $\mathrm{O}_{3}$ at midlatitudes.

[11] To provide appropriate boundary conditions to the nested Amazon grid, the GEOS-5 meteorological data is degraded to a $4^{\circ} \times 5^{\circ}$ horizontal resolution and a global simulation performed, with the tracer mixing ratios saved every $3 \mathrm{~h}$ (consistent with the temporal resolution of the surface meteorology). The archived tracer mixing ratios in coarse grid cells adjacent to the nested domain, are then supplied to a delineated buffer zone (of three $0.667^{\circ} \times 0.5^{\circ}$ grid cells width) in an area-weighting, grid-filled procedure (as described by Wang et al. [2004]) to give the dynamic boundary constraints.

\subsection{Chemical Mechanism}

[12] The standard GEOS-Chem chemical mechanism provides a relatively detailed treatment of coupled $\mathrm{O}_{3}-\mathrm{NO}_{\mathrm{x}}-\mathrm{VOC}$ and aerosol chemistry [Horowitz et al., 1998; Bey et al., 2001; Fiore et al., 2002; Park et al., 2004] integrated using the Kinetic Preprocessor (KPP) solver of Sandu and Sander [2006]. Emissions from anthropogenic, biogenic and pyrogenic sources are provided, and the explicit photo-oxidation schemes of methane, ethane, propane, lumped $>\mathrm{C}_{3}$ alkanes, lumped $>\mathrm{C}_{2}$ alkenes and isoprene are considered, with organic peroxides recycled [see Palmer et al., 2003; Fiore et al., 2005]. Details of non-BVOC emissions are described separately in the auxiliary material; their annual emissions for 2006 are summarized in Table 1. Photolysis rates are calculated using the Fast-J algorithm of Wild et al. [2000], which takes into account Rayleigh scattering as well as Mie scattering by aerosols and clouds. Dry deposition of aerosols and gases are based on a standard resistance-in-series model [Wesely, 1989] as described by Wang et al. [1998]. We update the model to include the deposition of six extra species (isoprene, methyl vinyl ketone (MVK), methacrolein (MACR), acetone, acetaldehyde and methyl hydroperoxide) based on their Henry's Law constant and a reactivity factor, using values consistent with the study of von Kuhlmann et al. [2004]; Table 2 summarizes the dry deposition losses for 2006. Wet deposition (rainout and washout) of aerosols and gases are described by Liu et al. [2001] and Mari et al. [2000], respectively. In addition to the standard GEOS-Chem chemical scheme, an alternative mechanism (hereafter referred to as the Caltech mechanism) has been devised following the detailed work of Paulot et al. [2009a, 2009b]. This scheme includes a more explicit treatment of the production of organic nitrates, acids and epoxides from the photo-oxidation of isoprene, and contains an extra 13 transported species and approximately 50 more photochemical reactions. The formation of epoxides is of particular relevance to the Amazon region, given that extra $\mathrm{OH}$ is regenerated in low $-\mathrm{NO}_{\mathrm{x}}$ conditions [Paulot et al., 2009a].

[13] We include a sensitivity test, discussed in section 4, to quantify the effect of artificial $\mathrm{OH}$ recycling as proposed by Lelieveld et al. [2008], by modifying within each scheme the reaction of first generation isoprene peroxy $\left(\mathrm{ISOPO}_{2}\right)$ and hydroperoxyl $\left(\mathrm{HO}_{2}\right)$ radicals, in the formation of isoprene hydroxy peroxides (ISOPOOH) as follows:

$$
\mathrm{ISOPO}_{2}+\mathrm{HO}_{2} \rightarrow \mathrm{ISOPOOH}+n \mathrm{OH}+\ldots
$$

In this study we set $n=2$ given the uncertainty reported in recent literature [Butler et al., 2008; Kubistin et al., 2010; Pugh et al., 2010; Stavrakou et al., 2010]. Consistent with these previous studies, we also reduce the rate coefficient of the isoprene and $\mathrm{OH}$ reaction (here by $10 \%$ ), owing to possible segregation effects due to incomplete mixing [ Krol et al., 2000; Karl et al., 2007], acknowledging this rate reduction is highly uncertain and likely to vary considerably within the real atmosphere.

[14] Owing to the recent updates made to the chemical mechanism [e.g., Millet et al., 2010; Paulot et al., 2009a, 2009b], we reassess the GEOS-Chem HCHO yields from isoprene oxidation using the Master Chemical Mechanism (MCM) [Jenkin et al., 2003; Saunders et al., 2003] as our reference chemistry (see auxiliary material). The timedependent $\mathrm{HCHO}$ yields from the oxidation of a pulse release of 1 ppbv of isoprene are given in Table 3. They show that under high- $\mathrm{NO}_{\mathrm{x}}$ conditions $(\geq 1.0 \mathrm{ppbv})$ the new GEOSChem yields are similar to those previously published by Palmer et al. [2003, 2006]. The short-term HCHO yield (i.e., that achieved by the end of the first day) calculated by GEOS-Chem's standard and Caltech mechanisms are within $20 \%$ of the MCM value and comprise $98 \%$ and $91 \%$ of their ultimate yields, respectively. 
Table 2. GEOS-Chem Dry Deposition Losses Over the Amazon Domain for 2006 Based on the $S_{F M}$ Scenario $^{\text {a }}$

\begin{tabular}{lccc}
\hline \multicolumn{1}{c}{ Species ${ }^{\mathrm{b}}$} & $\begin{array}{c}\mathrm{Amount}^{\mathrm{c}} \\
(\mathrm{Tg})\end{array}$ & $\begin{array}{c}\mathrm{v}_{d}{ }^{\mathrm{d}} \\
\left(\mathrm{cm} \mathrm{s}^{-1}\right)\end{array}$ & $\begin{array}{c}\text { Lifetime }^{\mathrm{e}} \\
(\text { days })\end{array}$ \\
\hline $\mathrm{NO}_{2}$ & 0.43 & 0.16 & 27 \\
$\mathrm{O}_{3}$ & 80.06 & 0.25 & 97 \\
$\mathrm{PAN}$ & 0.61 & 0.15 & 71 \\
Isoprene & 0.06 & 0.01 & 1054 \\
$\mathrm{HNO}_{3}$ & 4.01 & 1.52 & 10 \\
$\mathrm{H}_{2} \mathrm{O}_{2}$ & 14.32 & 0.69 & 9 \\
$\mathrm{Acetone}$ & 1.08 & 0.17 & 103 \\
$\mathrm{Acetaldehyde}$ & 0.30 & 0.51 & 24 \\
$\mathrm{MVK}$ & 3.62 & 0.16 & 9 \\
$\mathrm{MACR}$ & 3.32 & 0.16 & 9 \\
$\mathrm{PMN}_{\mathrm{PPN}}$ & 0.23 & 0.15 & 11 \\
$\mathrm{R}_{4} \mathrm{~N}_{2}$ & 0.02 & 0.15 & 151 \\
$\mathrm{HCHO}$ & 0.04 & 0.15 & 53 \\
$\mathrm{~N}_{2} \mathrm{O}_{5}$ & 6.10 & 0.51 & 9 \\
$\mathrm{MP}$ & 0.02 & 1.52 & 39 \\
\hline
\end{tabular}

\footnotetext{
${ }^{\mathrm{a}}$ See Table 5.

${ }^{\mathrm{b}}$ Species definition as follows: MVK, methyl vinyl ketone; MACR, methacrolein; MP, methyl hydroperoxide; PMN, peroxy methacryloyl nitrate; PPN, peroxypropionyl nitrate; $\mathrm{R}_{4} \mathrm{~N}_{2}, \mathrm{C}_{4}, 5$ alkyl nitrates.

${ }^{\mathrm{c}}$ Note that losses of isoprene, acetone, and acetaldehyde are in $\mathrm{Tg} \mathrm{C}$.

${ }^{\mathrm{d}}$ Average deposition velocity over land and ocean.

${ }^{\mathrm{e}}$ Average tropospheric lifetime against dry deposition.
}

[15] In low $-\mathrm{NO}_{\mathrm{x}}$ conditions $(\leq 0.1 \mathrm{ppbv})$, more relevant to our study domain, the short-term HCHO yields computed by the standard and Caltech mechanisms are within about $10 \%$ of the MCM yield and by the end of the day have reached $84 \%$ and $78 \%$ of their ultimate yield, respectively. This is a significant improvement on the studies of Palmer et al. [2003, 2006] since previously the GEOS-Chem yield was only within about $40 \%$ of the MCM after 1 day.

[16] Although the GEOS-Chem HCHO yields are broadly consistent with the MCM, the reader should be aware these model values only serve as an approximate guide, since they reflect significant uncertainties in BVOC oxidation chemistry. Furthermore, within the real atmosphere the yield depends on its local environment and is therefore likely to vary considerably [Palmer et al., 2003].

\section{BVOC Emissions}

[17] Since BVOC emissions from terrestrial vegetation are the primary driver of tropical oxidation chemistry, it is essential to model their emissions as accurately as possible. Most CTMs employ only a single BVOC emission inventory, typically one of the Guenther et al. [1995, 1999, 2006] algorithms, owing to their ease of use. In this work we go a step further by implementing two different isoprene emission inventories into GEOS-Chem, to quantify their impact on the subsequent $\mathrm{HCHO}$ column distributions. The first inventory we use is MEGAN [Guenther et al., 2006], which is canopyscale model. The second inventory is a leaf-scale emission algorithm developed by Arneth et al. [2007a, 2010] which is coupled to the Lund-Potsdam-Jena General Ecosystem Simulator (LPJ-GUESS) dynamic vegetation model [Smith et al., 2001]. The main difference between these models is that MEGAN is based on extrapolating available leaf/branch enclosure measurements and ecosystem observations (using a canopy model), to derive areal basal canopy emission factors. Note that for the Amazon region the emission factors are solely based on above-canopy measurements. These standardized emission capacities are coupled to static vegetation maps, with emission variability modeled using empirical algorithms forced by external meteorology and seasonal estimates of leaf area. Alternatively, within LPJ-GUESS analogues to leaf level emission capacities are assigned per plant functional type (PFT), and short-term emission variability in response to temperature and light modeled using semimechanistic algorithms that link emissions to their chloproplastic production. The scaling to canopy, seasonal changes in leaf area index, and PFT distributions are explicitly calculated permitting ecosystem emissions to be estimated. In sections 3.1 and 3.2, we outline the details of each model and then provide a comparison of their respective emissions for the Amazon region in section 3.3.

\subsection{MEGAN Emissions}

[18] The latest MEGAN release (version 2.1) [Guenther and Wiedinmyer, 2007; Sakulyanontvittaya et al., 2008] can calculate emission rates for 138 chemical species using 20 explicit and lumped chemical classifications. Here we focus only on the (explicit) species: isoprene, methylbutenol (MBO), and several monoterpene compounds ( $\alpha$ pinene, $\beta$ pinene, limonene, myrcene, sabinene, 3-carene, and ocimene). The emissions, $E$, of these compounds are parameterized by

$$
E=E_{0} \times \gamma_{C E} \times \gamma_{A g e} \times \gamma_{S M} \times \rho
$$

where $E_{0}$ are the basal emissions (in $\mu \mathrm{g}$ of compound $\mathrm{m}^{-2} \mathrm{~h}^{-1}$ ) normalized to standard conditions (current air temperature $=$ $303 \mathrm{~K}$, photosynthetic active radiation $(\mathrm{PAR})=1500 \mu \mathrm{mol}$ $\mathrm{m}^{-2} \mathrm{~s}^{-1}$, leaf area index $=5$ ), which are multiplied by emission activity factors that simulate changes in the emission rate owing to the changes in the canopy environment $\gamma_{C E}$, leaf age $\gamma_{A g e}$, and soil moisture $\gamma_{S M}$. In this study we neglect the effect of soil moisture $\left(\gamma_{S M}=1\right)$. Similarly, we assume standard conditions for any extra production or loss of the BVOC within the vegetation canopy by setting $\rho=1$. For isoprene, this implies typical canopy losses of about $4 \%$ [Guenther et al., 2006].

[19] In GEOS-Chem two different versions of MEGAN can be employed by switching on/off the relevant flags in the model control file. There are subtle but important differences between these model versions which are essentially based on the calculation of the canopy term $\gamma_{C E}$. The two models are as follows:

[20] 1. The PCEEA model is a simplified parameterized canopy environment emission activity (PCEEA) algorithm that is described in detail by Guenther et al. [2006] and Guenther and Wiedinmyer [2007]. Here $\gamma_{C E}$ is calculated by

$$
\gamma_{C E}=\gamma_{T} \times \gamma_{P A R} \times \gamma_{L A I},
$$

where $\gamma_{T}, \gamma_{P A R}$ and $\gamma_{L A I}$ are activity factors to account for the effect of current and past variations in temperature, light and leaf area on the emissions for the 'whole' canopy environment.

[21] 2. The hybrid algorithm model uses a combination of the new parameterizations of Guenther et al. [2006] and Guenther and Wiedinmyer [2007], and some older Guenther et al. [1995, 1999] algorithms. This hybrid model uses an 
explicit canopy model to calculate variations in light and leaf area at five sublayers (denoted by $l$ ) within the canopy. Here $\gamma_{C E}$ is calculated by

$$
\gamma_{C E}=\gamma_{T} \times \sum_{l=1,5} \gamma_{P A R^{\prime}} \times \mathrm{LAI}_{l}
$$

where $L A I_{l}$ is the cumulative leaf area index at layer $l$, and $\gamma_{P A R^{\prime}}$ is based on Guenther et al. [1999]. Note that (1) $\gamma_{T}$ calculated here is equivalent to the $\gamma_{T}$ in the PCEEA algorithm (equation (2)) and (2) in both approaches we also take into account the light dependency of monoterpenes based on the work of Sakulyanontvittaya et al. [2008].

[22] In standard GEOS-Chem simulations, the basal MEGAN emission factors are regridded from a default $0.5^{\circ} \times 0.5^{\circ}$ grid to the GEOS-Chem horizontal resolutions and driven by 3 hourly surface air temperatures (at $2 \mathrm{~m}$ height), and by diffuse and direct PAR from the GEOS-5 assimilation system. To simulate changes in vegetation we use gridded MODIS observations of monthly mean leaf area index (LAI) made over 2000-2008 (version C5; default resolution: $0.25^{\circ} \times 0.25^{\circ}$ ) [Myneni et al., 2007]. The average leaf area index for vegetated areas within each grid cell, LAI $_{v}$, is estimated by dividing the LAI by the fraction of the cell covered by vegetation following the approach of Guenther et al. [2006].

\subsection{LPJ-GUESS Emissions}

[23] LPJ-GUESS is a dynamic global vegetation modeling framework [Arneth et al., 2010] that combines process descriptions for plant and soil carbon and water cycling of LPJ [Sitch et al., 2003] with explicit formulation of vegetation resource competition for light and water and successional dynamics [Smith et al., 2001]. For global simulations, the model represents vegetation by 10 plant functional types. Among these, tropical forests and woodlands are simulated via a dynamically changing mix of the tropical broadleaf rain green and tropical broadleaf evergreen plant functional types, as well as understorey vegetation that can be either of the $\mathrm{C} 3$ or $\mathrm{C} 4$ photosynthetic pathway.

[24] Emissions of isoprene and monoterpenes are calculated following Arneth et al. [2007a] and Schurgers et al. [2009a]. Leaf production of these terpenoids is linked to photosynthetic electron flow, reflecting their metabolic pathway [Niinemets et al., 1999]. For monoterpene emissions from broadleaf and herbaceous plant functional types, LPJ-GUESS assumes a production-driven emission pattern, with little or no contribution from leaf storage pools [Kuhn et al., 2004; Bäck et al., 2005; Schurgers et al., 2009b]. The short-term variation of BVOC emissions is thus driven by variation in temperature and light, relatively similar to that described by more empirical algorithms such as MEGAN [Arneth et al., 2007b], whereas the overall emission totals and seasonal patterns are also greatly influenced by variation in leaf area index and overall vegetation productivity, and PFT composition. As LPJ-GUESS operates on a daily time step, estimates of subdaily variation were created by applying empirical temperature and light algorithms [Guenther et al., 1995] operating at 3 hourly time step to the emission daily totals.

[25] Since dynamic vegetation models need a spin-up period, the meteorological drivers light, precipitation and air temperature from the Climate Research Unit of the University of East Anglia (CRU, http://www.cru.uea.ac.uk/) were corrected by equivalent variables from the GEOS-5 forecast [Rienecker et al., 2008] to match the chemistry simulations. First, the grid points in the GEOS-5 data set, at a longitude spatial resolution of $0.667^{\circ}$, were matched with the corresponding closest grid point of the $0.5^{\circ} \mathrm{CRU}$ data set. Corrections at each grid point were based on monthly average values for the two data sets for the period January 2005 to December 2006. Based on the observed differences between the two data sets, a least squares fitting procedure was adopted, applying a general sinus function. The GEOS-5 (years 2005-2009) and GEOS-5 adjusted CRU values (years 1901-2004) were then used to follow the standard simulation protocol of 500 year spin-up period with detrended data and constant atmospheric $\mathrm{CO}_{2}$ concentration to compute equilibrium soil and vegetation carbon pools, followed by a 20th and early 21 st century simulation of vegetation dynamics and BVOC emissions [Sitch et al., 2003; Arneth et al., $2007 \mathrm{a}]$. We call this scenario $L P J(G C)$. In addition, to provide a reference point for the $L P J(G C)$ scenario, we also conducted a simulation in which vegetation dynamics and BVOC emissions are based on the default CRU meteorology alone, denoted $L P J(C R U)$.

\subsection{Comparison of MEGAN and LPJ-GUESS}

[26] Figures 2 and 3, which show the monthly mean emissions maps for 2006 and the time series of the monthly totals over 2005-2008, respectively, illustrate there are substantial spatial and temporal differences in the BVOC emissions predicted by the MEGAN and LPJ-GUESS inventories. Given the large uncertainties in modeling BVOC emissions [Arneth et al., 2008], we have to assume that all these estimates are plausible. The annual totals given in Table 4, show that for isoprene, the estimates lie almost within a factor of 2 of one another, consistent with known uncertainties of tropical emissions [Guenther et al., 2006]. Furthermore, the maximum monthly emissions, which range from 2.4 to $9.7 \mathrm{mg} \mathrm{m}^{2} \mathrm{~h}^{-1}$ during 2005-2006, are also consistent with previously reported measurements [see, e.g., Kuhn et al., 2007, and references therein]. The discrepancy between the monoterpene annual totals is more considerable; uncertainties in the basal emission rates and algorithm differences are the likely origin. For example, owing to the lack of storage, monoterpene emissions from broadleaf trees only occur during the day in the LPJ-GUESS model, whereas in MEGAN the emissions are continuous.

[27] Focusing on isoprene, we find the MEGAN hybrid and PCEEA algorithms (not unexpectedly) produce very similar emissions throughout the year, with very high emissions in the dry season (broadly August-November) owing to higher light levels and slightly warmer temperatures [Barkley et al., 2008]. Typically, MEGAN predicts the highest emissions along the Brazilian border with Peru and Bolivia, owing to a large percentage of high emitting species (e.g., bamboo forest) [Barkley et al., 2008]. Isoprene emissions from the MOHYCAN model [Müller et al., 2008], which also uses MEGAN, generally have a similar spatial distribution (a consequence of using same basal emission factors) but much lower annual totals, most likely owing to different choice of meteorology and canopy model, and through the 


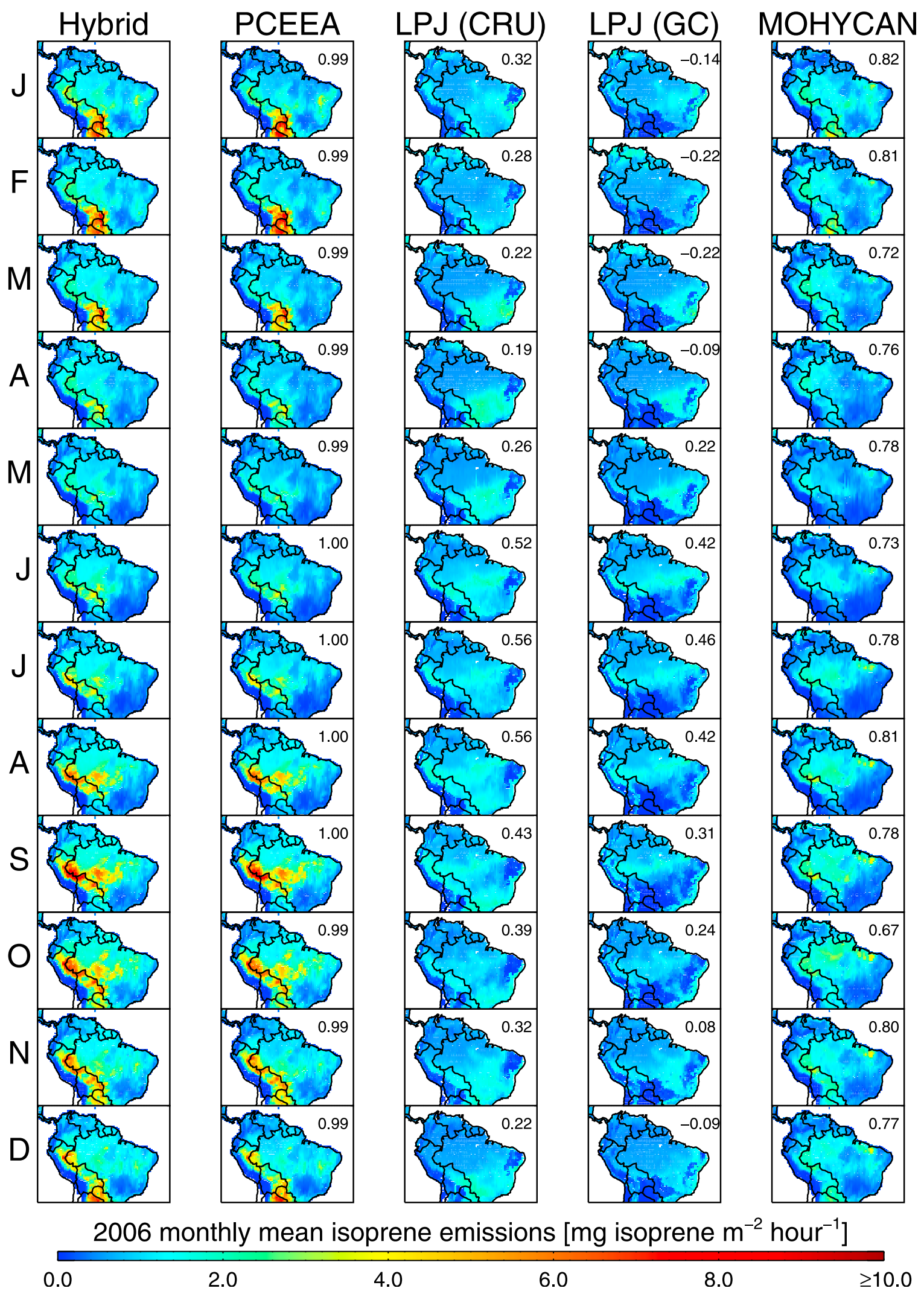

Figure 2. Monthly mean isoprene emissions for 2006 (in $\mathrm{mg}$ isoprene $\mathrm{m}^{-2} \mathrm{~h}^{-1}$ ) calculated by the MEGAN hybrid and PCEEA algorithms and the LPJ-GUESS model forced by the default CRU meteorology, LPJ (CRU), and the GEOS-5 meteorology, LPJ(GC). For comparison, the monthly mean emissions from the MOHYCAN model [Müller et al., 2008] remapped to the GEOS-Chem nested grid are also shown. The correlation of the emissions, relative to the MEGAN hybrid model, are shown inset. 


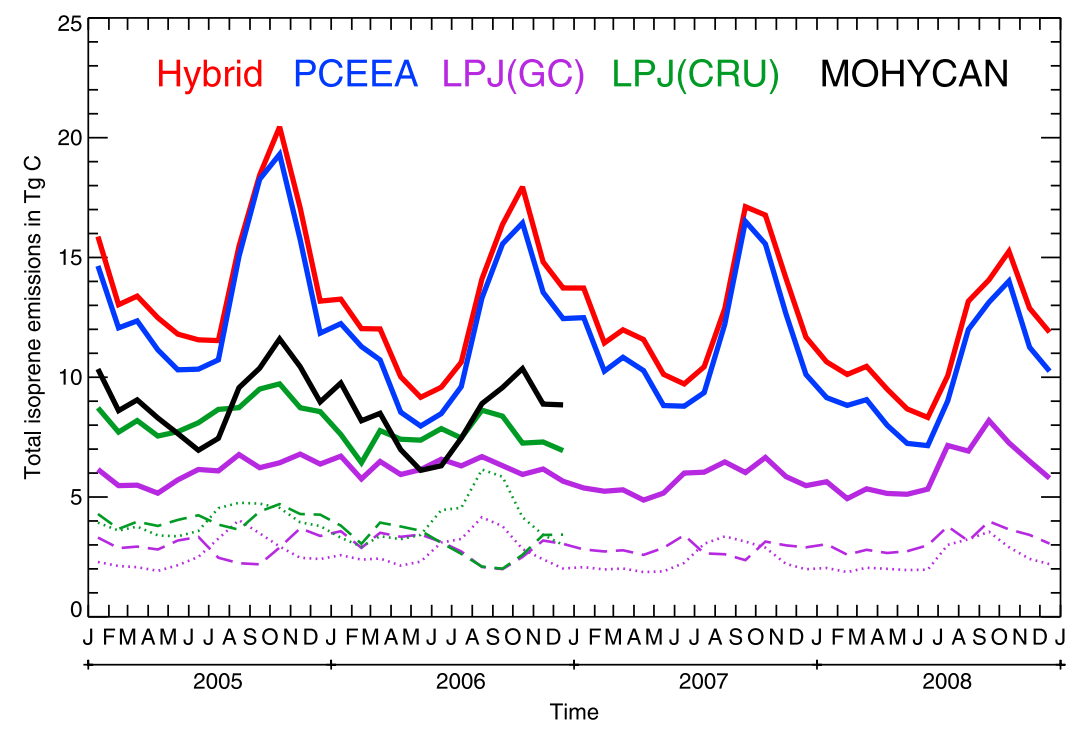

Figure 3. Time series of the total monthly isoprene emissions (in $\mathrm{Tg} \mathrm{C}$ ) calculated by the MEGAN hybrid (solid red line) and PCEEA (solid blue line) algorithms and the LPJ-GUESS model forced by the default CRU meteorology (solid green line) and the GEOS-5 meteorology (solid purple line). The purple and green dashed and dotted lines represent the LPJ emissions from tropical broadleaf evergreen and rain green trees, respectively. For comparison, the monthly totals calculated by the MOHYCAN model [Müller et al., 2008] are also shown (solid black line).

inclusion of the soil moisture activity factor (which we set to unity in equation (1)). Therefore, as Figure 2 clearly illustrates, the way MEGAN is implemented can produce sizeable differences between emission estimates, even on a regional basis.

[28] The LPJ-GUESS model produces lower emissions everywhere compared with the hybrid/PCEEA estimates, though when forced with the CRU meteorology the model yields monthly and annual totals that agree well with MOHYCAN (Figure 3). In the LPJ-GUESS simulations, the largest sources of isoprene are from broadleaf evergreen and rain green trees; emissions from temperate tree species and grasses are much lower (about $2-5 \%$ of emission total). The highest emissions tend to occur toward southeastern Brazil, where emissions from broadleaf rain green trees dominate during November-June. Outside this time period emissions from broadleaf evergreens are typically higher than emission from rain green trees, owing to a decrease in the latter's leaf area. Although on a continental scale the total emissions from either LPJ-GUESS simulation show little seasonal variation, indicating the Amazon is a constant emission source, a clear seasonal signal is evident for tropical broadleaf evergreens with higher emissions in the dry season and fairly constant emissions otherwise.

\section{Model Evaluation}

[29] Our validation strategy is based on using a combination of surface, aircraft and satellite observations to assess model performance. Each of these observing platforms are representative of differing spatial and temporal scales and through combined use we can effectively relate the surface concentrations of isoprene and its oxidation products to the satellite retrieval of the $\mathrm{HCHO}$ vertical column. In this work we focus on the observations made from two campaigns: (1) the Tropical Forest and Fire Emissions Experiment (TROFFEE) [Yokelson et al., 2007] undertaken in AugustSeptember 2004 and (2) the Guyanas Atmosphere-Biosphere Exchange and Radicals Intensive Experiment with the Learjet (GABRIEL) [Stickler et al., 2007] performed in October 2005.

[30] In addition to these in situ observations we use satellite data from SCIAMACHY and the Ozone Monitoring Instrument (OMI) [Levelt et al., 2006] to evaluate GEOS-Chem's ability to model the HCHO column distributions, from which

Table 3. Time-Dependent HCHO Yields per Carbon From the Oxidation of Isoprene ${ }^{\mathrm{a}}$

\begin{tabular}{|c|c|c|c|c|c|c|c|c|}
\hline \multirow[b]{2}{*}{ Chemical Scheme } & \multicolumn{4}{|c|}{$\mathrm{HCHO}$ Yield in High $\mathrm{NO}_{\mathrm{x}}$ Conditions } & \multicolumn{4}{|c|}{ HCHO Yield in Low $\mathrm{NO}_{\mathrm{x}}$ Conditions } \\
\hline & Midday & Afternoon & Midnight & 5 Days & Midday & Afternoon & Midnight & 5 Days \\
\hline MCM & 0.45 & 0.48 & 0.49 & 0.50 & 0.22 & 0.30 & 0.35 & 0.47 \\
\hline GEOS-Chem (standard) & 0.37 & 0.40 & 0.41 & 0.42 & 0.22 & 0.29 & 0.32 & 0.38 \\
\hline GEOS-Chem (Caltech) & 0.33 & 0.38 & 0.39 & 0.43 & 0.23 & 0.29 & 0.31 & 0.40 \\
\hline
\end{tabular}

${ }^{\mathrm{a}} \mathrm{HCHO}$ yields are calculated using the Master Chemical Mechanism (MCM) [Jenkin et al., 2003; Saunders et al., 2003] and the GEOS-Chem standard and Caltech schemes (see section 2.2) and correspond to the oxidation of 1 ppbv of isoprene released at 07:00 within a tropical environment. High- and low- $\mathrm{NO}_{\mathrm{x}}$ regimes are simulated by holding $\mathrm{NO}_{\mathrm{x}}$ constant at 1 and $0.1 \mathrm{ppbv}$, respectively. The afternoon yield is computed at 14:00; the yield after 5 days is taken to be the ultimate yield [see, e.g., Palmer et al., 2006]. 
Table 4. Total Annual Isoprene and Monoterpene Emissions From the Amazon Nested Grid for 2005-2008 as Calculated by the MEGAN Hybrid and PCEEA Algorithms and the LPJ-GUESS Model Using the GEOS-5 Meteorology and the Original CRU Meteorology

\begin{tabular}{|c|c|c|c|c|c|c|c|c|}
\hline \multirow[b]{3}{*}{ Algorithm } & \multicolumn{8}{|c|}{ Annual Emissions ( $\mathrm{Tg} \mathrm{C}$ ) } \\
\hline & \multicolumn{4}{|c|}{ Isoprene } & \multicolumn{4}{|c|}{ Monoterpenes } \\
\hline & 2005 & 2006 & 2007 & 2008 & 2005 & 2006 & 2007 & 2008 \\
\hline Hybrid & 174 & 154 & 152 & 135 & 32 & 30 & 30 & 28 \\
\hline PCEEA & 162 & 140 & 138 & 119 & 31 & 29 & 29 & 27 \\
\hline $\operatorname{LPJ}(\mathrm{GC})$ & 73 & 75 & 69 & 73 & 5 & 5 & 5 & 5 \\
\hline LPJ(CRU) & 102 & 90 & - & - & 7 & 6 & - & - \\
\hline MOHYCAN & 102 & 100 & - & - & - & - & - & - \\
\hline
\end{tabular}

${ }^{a}$ LPJ(GC), LPJ-GUESS model using the GEOS-5 meteorology; LPJ (CRU), LPJ-GUESS model using the original CRU meteorology. For comparison the total isoprene emissions calculated by the MOHYCAN model [Müller et al., 2008] are also included. Methylbutenol (MBO) emissions are negligible $(<0.1 \mathrm{Tg} \mathrm{C})$

a transfer function is derived to infer the top-down isoprene emissions [Barkley et al., 2008]. Details of these instruments and their respective retrieval algorithms are provided in the auxiliary material. The three most important distinctions between the sensors (relevant here) is the their coverage, overpass time, and ground pixel size. SCIAMACHY has a ground pixel size of $60 \times 30 \mathrm{~km}^{2}$ and a 10:00 local overpass time, with global coverage achieved at the equator every 6 days. OMI has a pixel size which ranges $14 \times 26 \mathrm{~km}^{2}$ to $28 \times 160 \mathrm{~km}^{2}$ (depending on viewing geometry), a 13:30 local overpass time and can achieve global coverage in a single day. Since OMI has a higher spatial resolution and better temporal coverage than SCIAMACHY, it has a lower measurement uncertainty owing to improved sampling statistics and reduced cloud contamination. In this work we restrict our model-satellite analysis to the year 2006 to save computational time; 2006 was chosen in preference to 2005 , owing to the strong drought that occurred in 2005 [Zeng et al., 2008].

[31] To determine the relative importance of model processes on the surface and column concentrations we performed a comprehensive set of sensitivity simulations with various key parameters changed or adjusted, as outlined in Table 5. Boundary conditions for each simulation were provided separately for the two GEOS-Chem chemical mechanisms, owing to the different number of reactive species and transported tracers within each scheme. Scenarios using the same chemical mechanism, but with different parameters changed (e.g., emissions) used the same boundary conditions, to ensure identical edge constraints and to save computational time. The spin-up period for each simulation, irrespective of the chemical scheme, originated from the same initialization time relevant to each study period. In this analysis we define our arbitrary baseline simulation, $\mathrm{S}_{F M}$, to which other scenarios are compared, as that using the standard chemical mechanism, full boundary layer mixing and with isoprene emissions based on the MEGAN hybrid algorithm.

\subsection{Comparison With TROFFEE Observations}

[32] The ground-based component of the TROFFEE campaign took place approximately $60 \mathrm{~km}$ NNW of Manaus in Central Amazonia. Measurements were performed on an instrumented flux tower (Z14: $2.6^{\circ} \mathrm{S}, 60.2^{\circ} \mathrm{W}, 55 \mathrm{~m}$ height) between 14 and 29 September 2004. The tower was surrounded by a forest of canopy height $30 \mathrm{~m}$ and with an average leaf area index of about 5-6. A proton transfer reaction mass spectrometry (PTR-MS) instrument situated on the tower was used in conjunction with the eddy covariance technique to infer the surface fluxes of isoprene and monoterpenes, and concentrations of isoprene and the sum of its

Table 5. Description of the GEOS-Chem Sensitivity Simulations

\begin{tabular}{|c|c|c|c|c|c|c|}
\hline \multirow[b]{2}{*}{ Scenario } & \multirow{2}{*}{$\begin{array}{c}\text { Chemical } \\
\text { Mechanism }\end{array}$} & \multicolumn{2}{|c|}{ Isoprene Emissions } & \multirow{2}{*}{$\begin{array}{l}\text { Boundary Layer } \\
\text { Mixing Scheme }\end{array}$} & \multirow{2}{*}{$\begin{array}{c}\mathrm{OH} \\
\text { Recycling }^{\mathrm{a}}\end{array}$} & \multirow{2}{*}{$\begin{array}{r}\text { Soil } \mathrm{NO}_{\mathrm{x}} \\
\text { Scaling }\end{array}$} \\
\hline & & Model & Scaling & & & \\
\hline $\mathrm{S}_{F M}$ & standard & MEGAN (hybrid) & 1.000 & full mixing & no & 1.00 \\
\hline $\mathrm{S}_{N L}$ & standard & MEGAN (hybrid) & 1.000 & nonlocal & no & 1.00 \\
\hline $\mathrm{S}_{F M(N O x)}$ & standard & MEGAN (hybrid) & 1.000 & full mixing & no & 1.25 \\
\hline $\mathrm{S}_{F M(r I E)}$ & standard & MEGAN (hybrid) & 0.635 & full mixing & no & 1.00 \\
\hline $\mathrm{S}_{F M(P C E E A)}$ & standard & MEGAN (PCEEA) & 1.000 & full mixing & no & 1.00 \\
\hline $\mathrm{S}_{F M(O H)}$ & standard & MEGAN (hybrid) & 1.000 & full mixing & yes & 1.00 \\
\hline $\mathrm{S}_{N L(O H)}$ & standard & MEGAN (hybrid) & 1.000 & nonlocal & yes & 1.00 \\
\hline $\mathrm{S}_{F M(L P J(C R U))}$ & standard & LPJ (CRU) & 1.000 & full mixing & no & 1.00 \\
\hline $\mathrm{S}_{F M(L P J(G C))}$ & standard & LPJ (GC) & 1.000 & full mixing & no & 1.00 \\
\hline $\mathrm{S}_{F M(r I E, O H)}$ & standard & MEGAN (hybrid) & 0.635 & full mixing & yes & 1.00 \\
\hline $\mathrm{C}_{F M}$ & Caltech & MEGAN (hybrid) & 1.000 & full mixing & no & 1.00 \\
\hline $\mathrm{C}_{N L}$ & Caltech & MEGAN (hybrid) & 1.000 & nonlocal & no & 1.00 \\
\hline $\mathrm{C}_{F M(N O x)}$ & Caltech & MEGAN (hybrid) & 1.000 & full mixing & no & 1.25 \\
\hline $\mathrm{C}_{F M(r I E)}$ & Caltech & MEGAN (hybrid) & 0.635 & full mixing & no & 1.00 \\
\hline $\mathrm{C}_{F M(P C E E A)}$ & Caltech & MEGAN (PCEEA) & 1.000 & full mixing & no & 1.00 \\
\hline $\mathrm{C}_{F M(\mathrm{OH})}$ & Caltech & MEGAN (hybrid) & 1.000 & full mixing & yes & 1.00 \\
\hline $\mathrm{C}_{\mathrm{NL}(\mathrm{OH})}$ & Caltech & MEGAN (hybrid) & 1.000 & nonlocal & yes & 1.00 \\
\hline $\mathrm{C}_{F M(L P J(C R U))}$ & Caltech & LPJ (CRU) & 1.000 & full mixing & no & 1.00 \\
\hline $\mathrm{C}_{F M(L P J(G C))}$ & Caltech & LPJ (GC) & 1.000 & full mixing & no & 1.00 \\
\hline $\mathrm{C}_{F M(r I E, O H)}$ & Caltech & MEGAN (hybrid) & 0.635 & full mixing & yes & 1.00 \\
\hline
\end{tabular}

${ }^{\mathrm{a}}$ See reaction $(\mathrm{R} 1)$.

${ }^{\mathrm{b}}$ Scaling factor is only applied to soil NO emissions; fertilizer emissions are unscaled. 


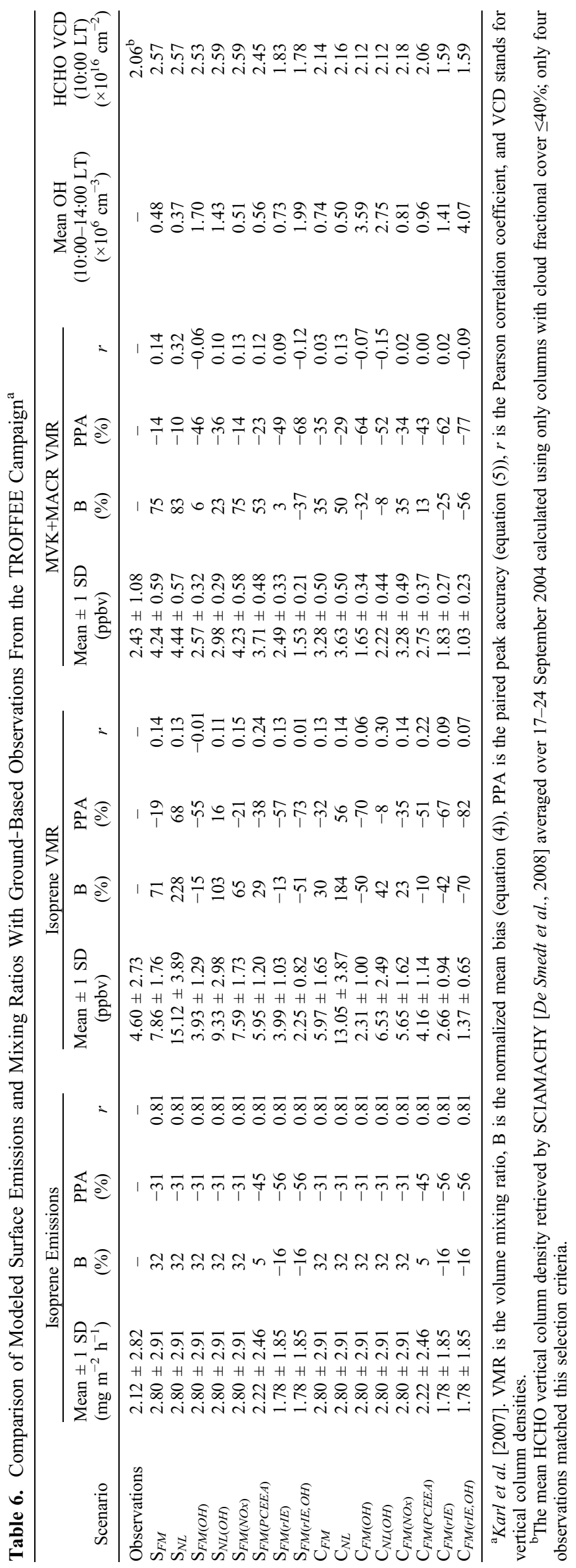

10 of 28 


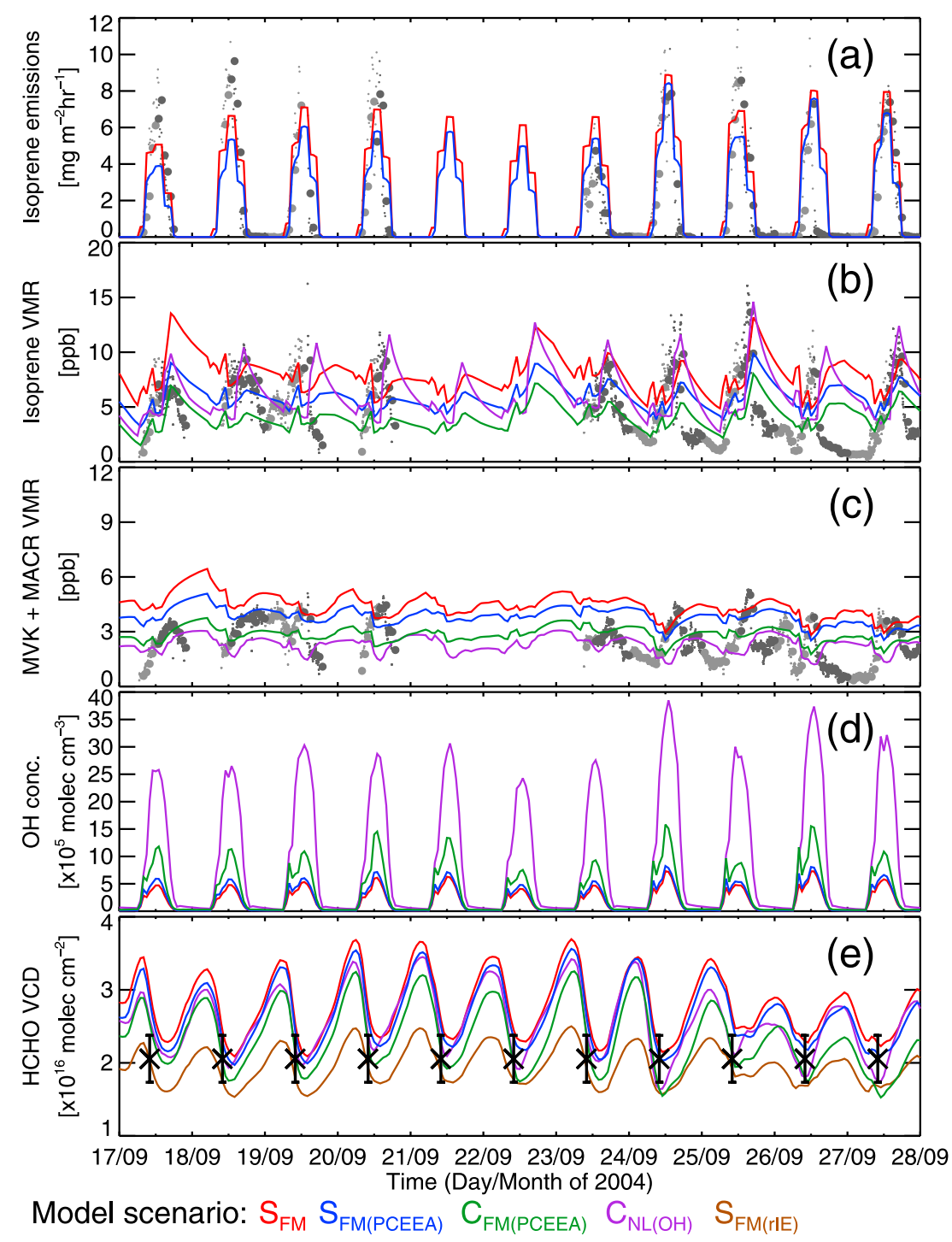

Figure 4. Comparison of model (a) isoprene emissions and surface mixing ratios of (b) isoprene and (c) MVK+MACR, with in situ tower measurements made in a primary forest reserve (tower $\mathrm{Z14}: 2.6^{\circ} \mathrm{S}$, $60.2^{\circ} \mathrm{W}$ ) as part of the TROFFEE campaign during 17-28 September 2004 [Karl et al., 2007]. For clarity we only show the $S_{F M}$ (red), $S_{F M(P C E E A)}$ (blue), $C_{F M(P C E E A)}$ (green), $C_{N L(O H)}$ (purple), and $S_{F M}$ $(r I E)$ (brown) simulations (see Table 5). Light and dark grey dots represent morning and afternoon observations, respectively; large dots are hourly averages, and small dots are the raw data. We also show the model's (instantaneous) hourly (d) surface OH concentrations and (e) HCHO vertical column densities (VCD), along with the mean SCIAMACHY observation (retrieved by De Smedt et al. [2008]) averaged at this model grid cell (over 17-27 September), shown as the black cross with \pm 1 standard deviation error bars.

oxidation products MVK and MACR. The instrumental setup and measurement procedure are discussed in detail by $\mathrm{Karl}$ et al. [2007]. For temporal consistency the observations were assembled into hourly means and compared to the hourly model output (adjusted to the local time) at the grid cell containing the tower location. All model runs were spun-up from 1 August 2004 (from a previously initialized 6 month simulation) to remove transient influences.

[33] Table 6 summarizes the main results of this comparison and Figure 4 shows the model and observed time series of surface isoprene fluxes, isoprene, $\mathrm{MVK}+\mathrm{MACR}$ and $\mathrm{OH}$ surface concentrations, and HCHO vertical columns. Here, and elsewhere, we use the normalized mean bias $(B)$

$$
B=100 \% \times \frac{\sum\left(\mathrm{M}_{\mathrm{i}}-\mathrm{O}_{\mathrm{i}}\right)}{\sum\left(\mathrm{O}_{\mathrm{i}}\right)}
$$

and the paired peak accuracy (PPA)

$$
P P A=100 \% \times \frac{\mathrm{M}\left(\mathrm{x}^{\prime}, \mathrm{t}^{\prime}\right)-\mathrm{O}\left(\mathrm{x}^{\prime}, \mathrm{t}^{\prime}\right)}{\mathrm{O}\left(\mathrm{x}^{\prime}, \mathrm{t}^{\prime}\right)},
$$


along with the Pearson correlation coefficient, $r$, to quantify the agreement between the modeled $(M)$ and observed $(O)$ quantities; $x^{\prime}$ and $t^{\prime}$ correspond to the location and time of the maximum observed value. The main results of this comparison can be summarized as follows:

\subsubsection{Isoprene Emissions}

[34] Figure 4a shows that at this location the MEGAN model reproduces the measured isoprene emissions fairly well (when taking into account the different spatial scales of the point measurements and the averaged grid cell emissions). Of the two MEGAN variants, the PCEEA model gives the best agreement to the observations, with a bias of less than $5 \%$, although it does not capture the peak values as well $(P P A=-45 \%)$. In contrast, the hybrid model better reproduces the peak emissions $(P P A=-31 \%)$, but has a much larger bias overall $(B=32 \%)$ as it tends to overestimate emissions during the early morning and latter part of the afternoon. The correlation is the same for both algorithms $(r=0.81)$. Scaling the hybrid emissions to those reported by Müller et al. [2008] reduces the bias by about half but increases the PPA. Since the LPJ-GUESS emissions were unavailable for the TROFFEE period, as an alternative, the hourly model emissions over 2005-2008 at this site were compared instead. We find that LPJ-GUESS estimates very rarely exceed the corresponding PCEEA or hybrid emissions (even when scaled to match the Müller et al. [2008] totals). A previous comparison by Arneth et al. [2007a] of the LPJ-GUESS emissions to the TROFFEE data also found lower model isoprene emissions than observed.

\subsubsection{Isoprene Surface Mixing Ratios}

[35] Figure $4 \mathrm{~b}$ shows that unlike the biogenic emissions, the isoprene mixing ratios are in general not reproduced well by GEOS-Chem, irrespective of the scenario employed. The observed isoprene mixing ratios demonstrate a pronounced diurnal cycle with midday peak values and a nocturnal minima. The absence of isoprene during the night indicates that most of the daytime emissions have been oxidized or deposited within the canopy. All scenarios fail to reproduce this diurnal pattern, as nighttime mixing ratios never approach zero, indicating that either (1) the model emissions are too high (clearly not the case), (2) the emitted isoprene has not been completely oxidized or has been poorly mixed out of the bottom model layer, or (3) we are missing a substantial nocturnal sink, e.g., surface deposition [Karl et al., 2010]. The range of simulated isoprene mixing ratios is large (1-15 ppbv) suggesting that even the supposedly simple transition from emissions to surface mixing ratios can be seriously distorted by individual or any potential combination of model processes. Of the scenarios tested, the $C_{F M(P C E E A)}$ has the smallest bias $(B=-10 \%)$ but doesn't capture the peak isoprene mixing ratios $(P P A=-51 \%)$; the correlation between the model simulations and measurements is always poor $(r<0.3)$. In addition, as Figure $4 \mathrm{~b}$ shows, the timing of the daytime peak emissions is not well captured, regardless of the choice of chemical or boundary layer mixing scheme. 4.1.3. MVK+MACR Surface Mixing Ratios

[36] The measured MVK+MACR mixing ratios also demonstrate a clear diurnal cycle which GEOS-Chem fails to reproduce (Figure 4c). Although the spread of the simulated mean mixing ratio is smaller than found for isoprene, the correlations are worse and even negative in some cases. Typically the modeled MVK+MACR mixing ratios are overestimated during the night and underestimated throughout the day, and show very little diel variation.

4.1.4. Mean Surface OH Concentrations

[37] The mean $\mathrm{OH}$ concentrations between 10:00 and 14:00 local time (LT) differ greatly, as shown in Figure 4d, and are primarily dependent on the chemical mechanism used and the inclusion of artificial $\mathrm{OH}$ recycling [Lelieveld et al., 2008]. Although the Caltech chemical mechanism generates slightly more $\mathrm{OH}$ than the standard GEOS-Chem chemistry scheme, it is only through the $\mathrm{OH}$ recycling, via reaction R1, that the model really stimulates high $\mathrm{OH}$ levels. For example, the mean $\mathrm{OH}$ concentrations for the $S_{F M}$ and $C_{F M}$ simulations are 0.48 and $0.74 \times 10^{6}$ molecules $\mathrm{cm}^{-3}$, respectively, but when $\mathrm{OH}$ recycling is included as in the $S_{F M(\mathrm{OH})}$ and $C_{F M(\mathrm{OH})}$ scenarios, levels reach 1.70 and $3.59 \times$ $10^{6}$ molecules $\mathrm{cm}^{-3}$. Despite this extra $\mathrm{OH}$ production, the model values are still relatively low compared with the observed range of values reported in the literature, typically 3-8 $\times 10^{6}$ molecules $\mathrm{cm}^{-3}$ [see, e.g., Kuhn et al., 2007; Lelieveld et al., 2008]. Hydroxyl concentrations can also be enhanced by a factor of 1.5-1.9 through simply reducing the isoprene emissions, as in the $S_{F M(r I E)}$ and $C_{F M(r I E)}$ simulations, owing to isoprene's significant $\mathrm{OH}$ reactivity.

\subsubsection{HCHO Vertical Column}

[38] Figure 4e reveals the model HCHO columns show a diurnal variation in response to both the surface emissions and oxidation chemistry, and to also the variation in the PBL depth. The HCHO columns have a maximum during the night when the PBL height is at its shallowest and a minimum in the day when the PBL has grown to its maximum extent. The choice of chemical scheme and baseline isoprene emissions have the greatest influence on the magnitude of the model HCHO columns. The standard chemical mechanism always produces larger $\mathrm{HCHO}$ columns than both the Caltech scheme and the mean SCIAMACHY HCHO column retrieved at this location (see Table 6). The Caltech mechanism yields $\mathrm{HCHO}$ columns much closer in agreement to the SCIAMACHY HCHO column, and in the case of the $C_{F M(P C E E A)}$ scenario produces an exact match at the time of the satellite overpass. Down scaling the hybrid isoprene emissions to the Müller et al. [2008] estimates results in lower-HCHO columns at the time of the SCIAMACHY overpass, but which fall closer to the \pm 1 standard deviation limits of the observed SCIAMACHY column.

\subsubsection{Discussion of TROFFEE Analysis}

[39] To better understand the processes leading to the modeled diurnal cycle of HCHO columns, we show in Figure 5 time versus altitude plots for the model output in the lowermost $3 \mathrm{~km}$ of the atmosphere for the days 18-20 September. In the early morning when sunlight initiates the emissions, isoprene is continually emitted and mixed throughout the PBL and isoprene oxidation by $\mathrm{OH}$ dominates production of $\mathrm{HCHO}$. Isoprene mixing ratios are usually quite low at midday when $\mathrm{OH}$ production is a maximum. However, in the late afternoon and early evening when the PBL decreases in height, isoprene and its oxidation products that are not destroyed earlier in the day are lofted above the falling boundary layer (which at night dips beneath the depth of the first model layer adjacent to the surface). Here they can accumulate at night and be further oxidized by ozone and the nitrate radical. In particular, there is a very large buildup of MVK, MACR, and HCHO during the night 


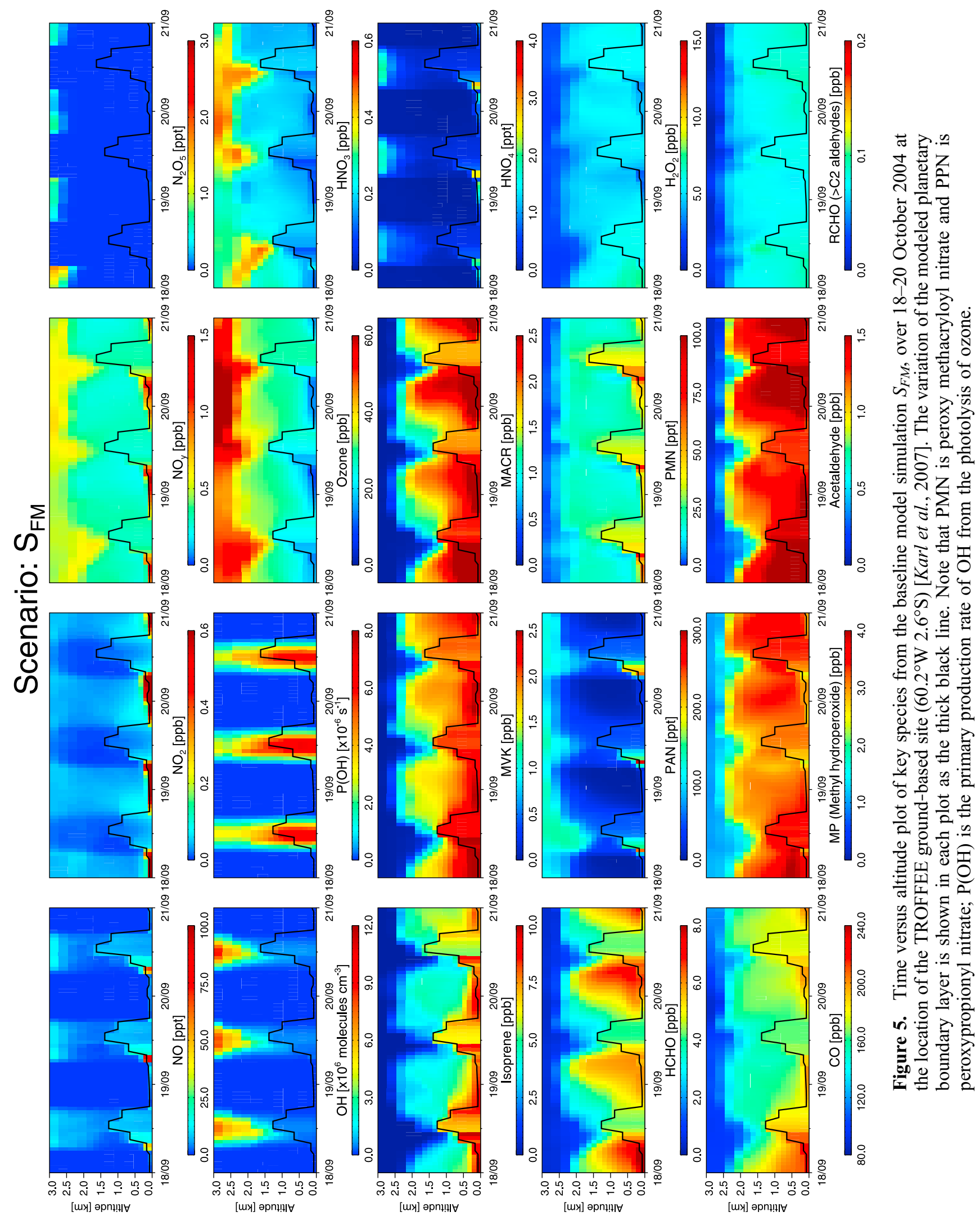


even at altitudes as high as $2 \mathrm{~km}$. In the early morning when the inversion breaks down, these accumulated species are then entrained into the rising boundary layer during the onset of daytime photochemistry. Hence, during the early morning, there is an extra 'nocturnal' source of $\mathrm{HCHO}$ within the boundary layer in addition to that produced from the photooxidation of the newly activated isoprene emissions. During the day, photolysis and oxidation by $\mathrm{OH}$ partly removes the MVK, MACR, and $\mathrm{HCHO}$ that has accumulated at higher altitudes during the night. Thus in our baseline simulation, high levels of isoprene and $\mathrm{HCHO}$ are not just constrained to the boundary layer but can exist up to about $2 \mathrm{~km}$ throughout the day. The night time accumulation of isoprene oxidation products in the residual layer and the failure of GEOS-Chem to vertically resolve the nocturnal PBL most likely results in the overestimation of the daytime $\mathrm{HCHO}$ columns. The entrained oxidation products also affect daytime isoprene oxidation, as they represent an additional sink for $\mathrm{OH}$ [Ganzeveld et al., 2008]. High levels of MVK, MACR, and HCHO within the tropical nocturnal residual layer have also been reported in other studies [see, e.g., Ganzeveld et al., 2008; Pugh et al., 2010]; we discuss this feature more in section 5 .

[40] Whilst changing a model parameterization may not appear to have a great effect on the HCHO column, and could be considered unimportant, it can greatly affect surface mixing ratios of isoprene and other key trace species (see, e.g., Figures S1-S3 and Text S1 within the auxiliary material). However, based on this set of simulations, we find the magnitude of the HCHO columns at this location are most sensitive to the surface isoprene emissions and chemical mechanism.

\subsection{Comparison With GABRIEL Observations}

[41] The GABRIEL aircraft campaign took place over Suriname, French Guiana and Guyana $\left(3^{\circ}-6^{\circ} \mathrm{N}, 51^{\circ}-59^{\circ} \mathrm{W}\right)$ during October 2005, coinciding with the region's dry season. During this month southeasterly trade winds transported clean Atlantic air masses westward where they were then subjected to significant reactive exchange over pristine tropical forests. Flights were performed over both land and ocean, sampling in the boundary layer and free troposphere (approximately $300 \mathrm{~m}$ to $10 \mathrm{~km}$ ). The GABRIEL mission was unique, in that both $\mathrm{OH}$ and $\mathrm{HO}_{2}$ were measured for the first time, along with a suite of VOC and oxygenated compounds. Overviews of the mission are given by Stickler et al. [2007] and Lelieveld et al. [2008]; more detailed descriptions of the airborne instrumentation and measurement procedures are described elsewhere [Williams et al., 2007; Gebhardt et al., 2008; Eerdekens et al., 2009; Martinez et al., 2010].

[42] To facilitate a meaningful comparison, we sample the model at the measurement times and locations along each flight track. Data from all flights were then averaged into $500 \mathrm{~m}$ bins (between 0 and $8 \mathrm{~km}$ ) and the resulting profiles compared. We show the model and observed vertical profiles in Figure 6 and provide a statistical summary for the lowest $0-2 \mathrm{~km}$ of the atmosphere in Table S1 (see auxiliary material). The main results are as follows:

\subsubsection{Isoprene Emissions}

[43] Eerdekens et al. [2009] derived a mean surface isoprene emission flux from the measured concentrations of isoprene and its oxidation products of $6.9 \mathrm{mg} \mathrm{m}^{-2} \mathrm{~h}^{-1}$ for the Guyana rainforest, after compensating for chemistry and detrainment. Model emissions spatially averaged over the GABRIEL domain and temporally averaged over 11:0013:00 LT, were slightly lower than this inferred value being $4.2,4.0,2.5,4.0$, and $2.0 \mathrm{mg} \mathrm{m}^{-2} \mathrm{~h}^{-1}$ for the hybrid, PCEEA, hybrid-scaled, LPJ(CRU), and LPJ(GC) algorithms, respectively.

\subsubsection{Isoprene}

[44] There is a large spread in the isoprene mixing ratios simulated by GEOS-Chem (0.3-2.2 ppbv), though they mostly fall within the \pm 1 standard deviation of the mean observation. Generally, the model captures the shape of the observed isoprene observations $(r>0.9)$, although the measurements demonstrate a slower falloff with altitude. Several simulations (e.g., $\left.S_{F M}, S_{F M(N O x)}, C_{F M(L P J(C R U))}\right)$ show very close agreement to the observations, whilst other scenarios, particularly those with $\mathrm{OH}$ recycling or with the lowest isoprene emissions, exhibit significant model bias.

\subsubsection{MVK+MACR}

[45] As with isoprene, the modeled MVK+MACR mixing ratios decrease faster with altitude than the observations; typically the profile differences are of order $0.5 \mathrm{ppbv}$. For simulations using the standard chemical scheme, there is a large variation in the simulated mixing ratios. Some scenarios have low overall bias but cannot capture the peak value well (e.g., $S_{F M}$ or $S_{N L}$ ), other scenarios capture the peak but have a significant bias (e.g., $S_{F M(\mathrm{OH})}$ or $S_{\mathrm{NL}(\mathrm{OH})}$ ). In contrast, the Caltech mechanism always produces an underestimation of the MCK+MACR mixing ratios and has a greater bias (approximately $-20 \%$ to $-70 \%$ ).

\subsubsection{HCHO}

[46] Although the model simulations capture the observed $\mathrm{HCHO}$ vertical distribution, there is almost always a positive model bias. Below $1.5 \mathrm{~km}$ the modeled mixing ratios are of order 1-1.5 ppbv greater than aircraft measurements; above $1.5 \mathrm{~km}$, the difference between the model and observations is small. Simulations using the Caltech mechanism consistently yield better agreement to the observations (unless $\mathrm{OH}$ recycling is included) than standard chemistry simulations. The $C_{F M(P C E E A)}$ scenario has the lowest overall bias $(B=3 \%$, $P P A=8 \%$ ).

\subsection{5. $\mathrm{OH}$ and $\mathrm{HO}_{2}$}

[47] GEOS-Chem consistently underestimates the observed $\mathrm{OH}$ and $\mathrm{HO}_{2}$ concentrations by about $-20 \%$ to $-60 \%$. Only the Caltech mechanism with additional $\mathrm{OH}$ recycling, produces $\mathrm{OH}$ levels anywhere near those measured (e.g., scenario $C_{F M(r I E, O H)}$ yields $B=-17 \%$ and $\left.P P A=-17 \%\right)$. The general disagreement with the $\mathrm{OH}$ and $\mathrm{HO}_{2}$ observations, suggests $\mathrm{HO}_{\mathrm{x}}$ is inadequately generated and/or recycled in either model mechanism. It should be noted however, that above $3 \mathrm{~km}$ the differences between the modeled and observed $\mathrm{HO}_{2}$ concentrations are fairly small.

\subsubsection{Ozone}

[48] The model reproduces the observed ozone vertical distribution reasonably well. The standard mechanism produces a closer match to observations below $2 \mathrm{~km}$, whereas the Caltech mechanism overestimates mixing ratios near the surface but better captures the ozone profile at higher altitudes. As shown in Figure 6, the wide variety of different model scenarios tested have almost negligible impact on the simulated ozone mixing ratios. 

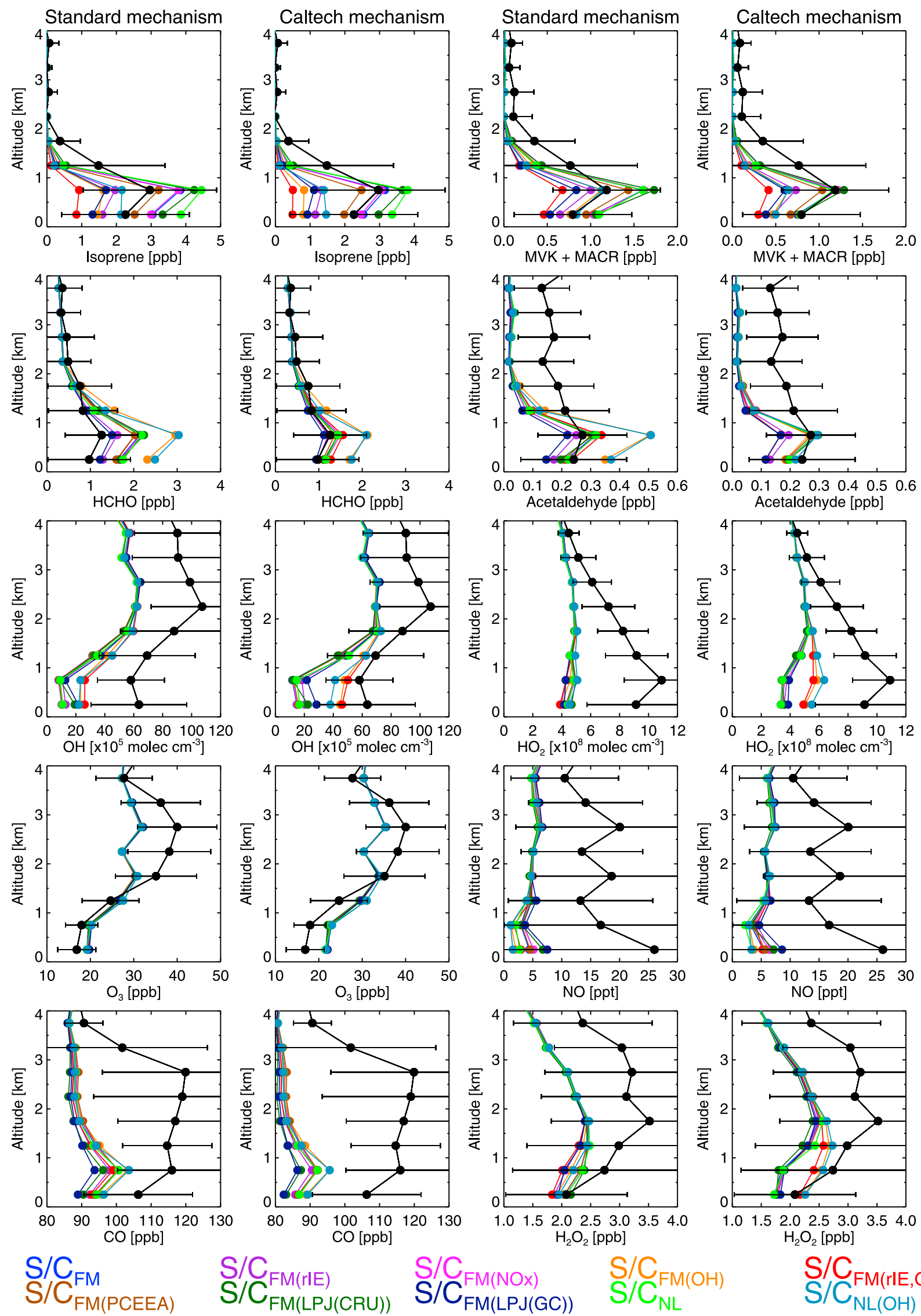

$S / C_{F M(r \mid E)}$
$S / C_{F M(L P J(C R U))}$

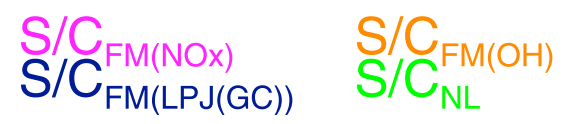

$\mathrm{S} / \mathrm{C}_{\mathrm{FM}(\mathrm{rlE}, \mathrm{OH})}$
$\mathrm{S} / \mathrm{C}_{\mathrm{NL}(\mathrm{OH})}$

Figure 6 


\subsubsection{NO and $\mathrm{CO}$}

[49] NO is significantly underestimated by GEOS-Chem. Increasing soil $\mathrm{NO}_{\mathrm{x}}$ emissions or using the Caltech chemical mechanism does little to alleviate this discrepancy. This negative bias may partially explain why model $\mathrm{OH}$ concentrations are also so low since the reaction of $\mathrm{NO}$ with $\mathrm{HO}_{2}$ is a pathway for $\mathrm{OH}$ regeneration (if there is sufficient $\mathrm{NO}_{\mathrm{x}}$ available). GEOS-Chem also fails to reproduce the observed $\mathrm{CO}$ distribution and typically underestimates the mixing ratios by 20 ppbv or more (i.e., $B=-15 \%$ to $-30 \%$ ). 4.2.8. Acetaldehyde and $\mathrm{H}_{2} \mathrm{O}_{2}$

[50] Formation of hydrogen peroxide $\left(\mathrm{H}_{2} \mathrm{O}_{2}\right)$ is an important sink for $\mathrm{HO}_{2}$, especially in low- $\mathrm{NO}_{\mathrm{x}}$ environments. Near the surface GEOS-Chem captures the observed $\mathrm{H}_{2} \mathrm{O}_{2}$ mixing ratios well, when using the standard chemical scheme, but simulates lower values than the measurements at higher altitudes. The Caltech chemistry scheme generates lower levels of $\mathrm{H}_{2} \mathrm{O}_{2}$ near the surface on average, unless $\mathrm{OH}$ recycling is included. Observed acetaldehyde mixing ratios are also captured reasonably by GEOS-Chem near the surface, but at higher altitudes are also underestimated.

\subsubsection{Discussion of GABRIEL Analysis}

[51] From this evidence it is clear that GEOS-Chem has difficulty in simulating several key chemical species measured during the GABRIEL campaign. In particular, $\mathrm{HO}_{\mathrm{x}}$, $\mathrm{H}_{2} \mathrm{O}_{2}$, NO and $\mathrm{CO}$ are all underestimated by the model, even with the more comprehensive Caltech chemical mechanism, whilst isoprene, MVK+MACR, and $\mathrm{HCHO}$ are generally overestimated. For isoprene and its oxidation products there is a large variation in the modeled values, indicating a high degree of sensitivity to the choice of model chemistry, emissions and boundary layer mixing. The observed slower decrease in the mixing ratios with altitude, suggests that either the vertical mixing within the boundary layer is underestimated or that the height of PBL is incorrect. Observed boundary layer heights, derived from potential temperature and water vapor measurements, were estimated to be approximately $500 \mathrm{~m}$ and $1450 \mathrm{~m}$ over land and $460 \mathrm{~m}$ and $500 \mathrm{~m}$ over ocean at 09:00 and 15:00 LT, respectively [Eerdekens et al., 2009]. The corresponding model PBL heights were $571 \mathrm{~m}$ and $1188 \mathrm{~m}$ over land, and $723 \mathrm{~m}$ and $718 \mathrm{~m}$ over ocean, averaged over 08:00-10:00 and 14:0015:00 LT, respectively. Therefore the underestimation of the model PBL height overland potentially yields higher tracer mixing ratios than observed, given that the dilution volume for reactive emissions and chemical species is smaller. As noted by Eerdekens et al. [2009] and Ganzeveld et al. [2008], the true altitude to which species were mixed, referred to as the mixed layer (ML) depth, was actually at least $1900 \mathrm{~m}$ which further decreases surface emissions and boundary layer mixing ratios. As the full- or nonlocal mixing schemes are constrained to the dynamic PBL height, neither mix tracers to the higher ML depth which may account for the higher than observed model values. Above the PBL, both MVK+MACR and HCHO are higher than the simulated values which may suggest convective transport is also underestimated within this region.

[52] To understand the subsequent impact of this poor model agreement on the simulated HCHO columns, we relate the aircraft measurements to the satellite observations by additionally sampling the model along a longitudinal transect $\left(45-60^{\circ} \mathrm{W} ; 4.5^{\circ} \mathrm{N}\right)$ directly across the flight paths, averaging the HCHO columns over 09:00-11:00 and 12:0015:00 LT to coincide with the overpass times of the respective SCIAMACHY (10:00 LT) and OMI (13:30 LT) instruments. We show the variation of the satellite and model $\mathrm{HCHO}$ columns along the transect in Figure 7. Both GEOS-Chem and the satellite observations agree on the transect gradient, with larger HCHO columns over land than ocean. Compared with the SCIAMACHY observations, simulations using the standard chemical scheme underestimate the observed HCHO columns over the ocean but overestimate them over land; model runs performed using the Caltech chemistry option are consistently lower than the retrieved $\mathrm{HCHO}$ column measurements. The spread of the relative difference, i.e., $(M-O) / O$, of the model columns $(M)$ compared to the SCIAMACHY data $(O)$ is considerable: $-50 \%$ to $50 \%$. When compared with the OMI HCHO column data, the Caltech chemical scheme produces a better match to the observations as the magnitude of the relative difference is mostly $<25 \%$. The standard chemical scheme performs worse with the relative difference typically $>25 \%$ (over land).

[53] In this context, it is not obvious why the observed differences in the HCHO profiles shown in Figure 6 of only 1-1.5 ppbv can translate to such a large deviations in the model HCHO columns. To illustrate why this is the case, we sequentially perturb two typical synthetic oceanic and continental $\mathrm{HCHO}$ profiles (below $1 \mathrm{~km}$ ) to assess the relative change in the HCHO vertical column. As shown in Figure 8, over the ocean where HCHO columns approach background levels, even a small increase of $\mathrm{HCHO}$ of $0.5 \mathrm{ppbv}$ within the lowest $1 \mathrm{~km}$ can create a $17 \%$ relative increase in the HCHO column; a 1 or 2 ppbv change results in increases of $33 \%$ or $66 \%$. Similarly, over land where HCHO columns are higher owing to VOC oxidation, a 1 or 2 ppbv perturbation creates a $20 \%$ and $40 \%$ relative change, respectively. In other words, a $20-30 \%$ model bias relative to a SCIAMACHY or OMI measurement will occur if GEOS-Chem fails to reproduce 'true' HCHO near surface mixing ratios within 1 ppbv (irrespective of any retrieval uncertainties). Therefore, the model should therefore at least attempt to simulate $\mathrm{HCHO}$ within boundary layer at the sub $1 \mathrm{ppbv}$ level, in order to ensure meaningful comparisons to satellite $\mathrm{HCHO}$ column observations.

\subsection{Comparison With Satellite HCHO Columns}

[54] To determine top-down isoprene emission with any confidence, it is a necessary prerequisite that the model

Figure 6. Observed and model vertical profiles over Suriname, French Guiana, and Guyana $\left(3^{\circ}-6^{\circ} \mathrm{N} 51^{\circ}-59^{\circ} \mathrm{W}\right)$ during the GABRIEL campaign in October 2005 [Stickler et al., 2007]. The model has been sampled at the same times and locations as the measurements and the data sets averaged into $500 \mathrm{~m}$ altitude bins. The observations are shown by the solid black lines with \pm 1 standard deviation error bars; the model simulations are represented by the solid color lines (see Table 5). Here $S / C_{F M}$ represents either $S_{F M}$ or $C_{F M}$ scenario (see Table 5). 

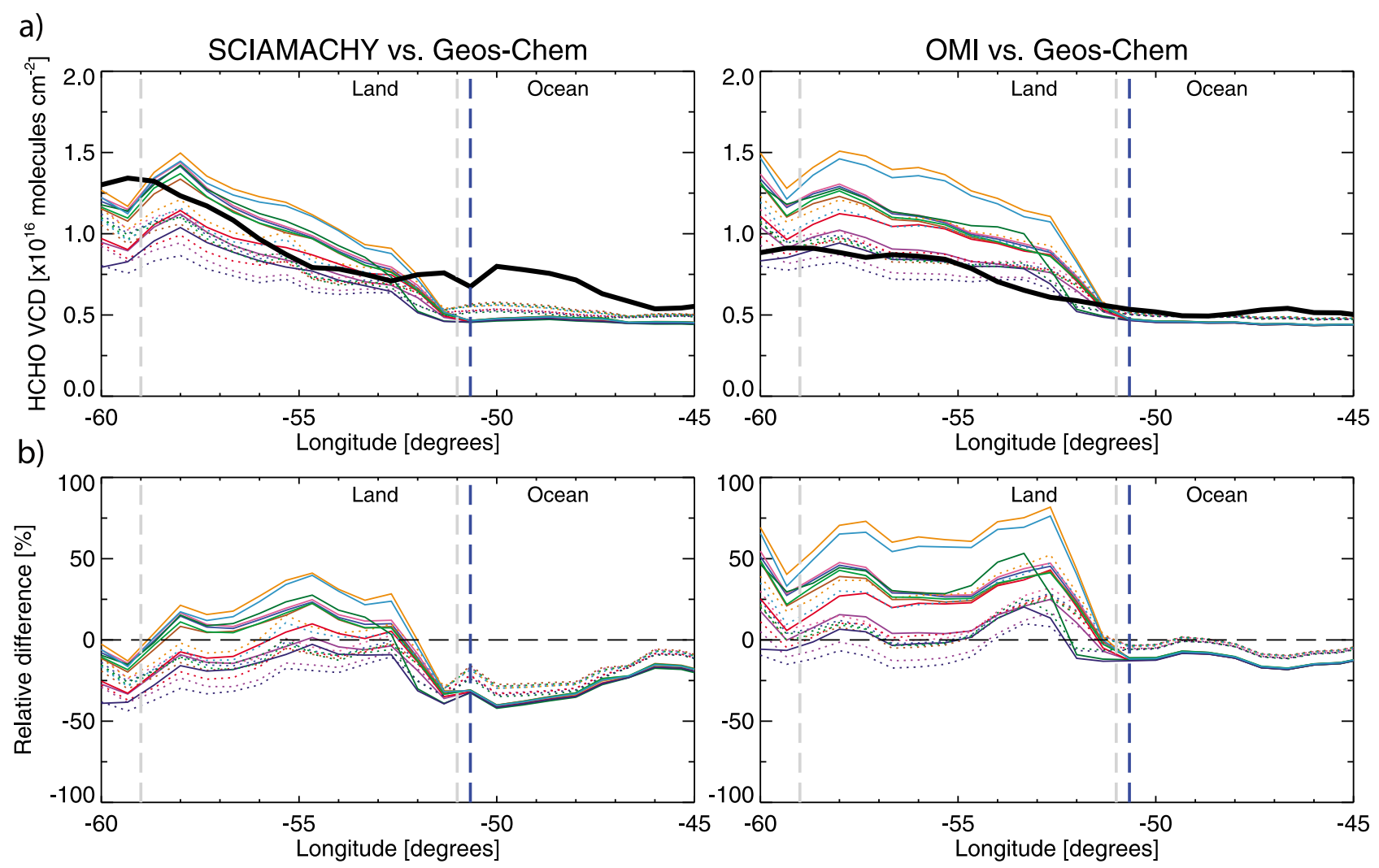

$$
\begin{array}{lllll}
\mathrm{S} / \mathrm{C}_{\mathrm{FM}} & \mathrm{S} / \mathrm{C}_{\mathrm{FM}(\mathrm{IIE})} & \mathrm{S} / \mathrm{C}_{\mathrm{FM}(\mathrm{NOX})} & \mathrm{S} / \mathrm{C}_{\mathrm{FM}(\mathrm{OH})} & \mathrm{S} / \mathrm{C}_{\mathrm{FM}(\mathrm{IIE}, \mathrm{OH})} \\
\mathrm{S} / \mathrm{C}_{\mathrm{FM}(\mathrm{PCEEA})} & \mathrm{S} / \mathrm{C}_{\mathrm{FM}(\mathrm{LPJ}(\mathrm{CRU}))} & \mathrm{S} / \mathrm{C}_{\mathrm{FM}(\mathrm{LPJ}(\mathrm{GC}))} & \mathrm{S} / \mathrm{C}_{\mathrm{NL}} & \mathrm{S} / \mathrm{C}_{\mathrm{NL}(\mathrm{OH})}
\end{array}
$$

Figure 7. Observed and modeled $\mathrm{HCHO}$ vertical columns along a longitudinal transect at $4.5^{\circ} \mathrm{N}$ during the GABRIEL campaign October 2005 [Stickler et al., 2007]. (left) HCHO columns averaged over 09:0011:00 LT corresponding with the overpass of SCIAMACHY (10:00 LT) (solid black line). (right) HCHO columns averaged over 12:00-15:00 LT corresponding with the overpass of OMI (13:30 LT) (solid black line). The model simulations using the standard and Caltech chemical mechanisms are represented by the solid and dashed color lines, respectively (see Table 5). (a) The mean HCHO columns (averaged over 317 October) and (b) the relative difference between the model and observations are shown. The SCIAMACHY and OMI HCHO data has been smoothed along the transect with a box filter (of nine grid cells width) to remove noise. The vertical grey lines represent the longitudinal limits of the Gabriel aircraft flights; the blue vertical line denotes the GEOS-Chem land-ocean crossover.

provides a reasonable simulation of the observed $\mathrm{HCHO}$ column spatial distributions. To establish whether this is the case, we show in Figures 9 and 10 the monthly mean SCIAMACHY and OMI HCHO distributions for 2006, along with the model output from the $C_{F M}, C_{F M(P C E E A)}$, $C_{F M(r I E)}, C_{F M(L P J(C R U))}$, and $C_{F M(L P J(G C))}$ scenarios. Here we sample the model at the same times and locations as the respective SCIAMACHY and OMI measurements and average the data in the same way (as described in the auxiliary material). We also show the time series of the monthly mean HCHO column statistics in Figure 11, and provide a summary of the annual mean statistics in Table 7.

[55] The SCIAMACHY observations show a pronounced seasonal cycle with high-HCHO columns in the dry season and low values in the wet-to-dry transitional period [Barkley et al., 2009]. When compared to the observations, the model demonstrates a large positive bias (often $>50 \%$ ), with simulations using the standard chemical mechanism performing much worse than those using Caltech scheme. Despite the model's positive bias, the various scenarios do not capture the observed maximum values well, often underestimating them except during March and September. Of the Caltech simulations, four scenarios yield much better results than the others: $C_{F M(r I E)}, C_{F M(L P J(C R U))}$, and $C_{F M(L P J(G C))}$ and $C_{F M(r I E, O H)}$. These scenarios have notably lower isoprene emissions than MEGAN as discussed in section 3, which may suggest the unscaled MEGAN emissions are too high. For example, the $C_{F M}$ and $C_{F M(P C E E A)}$ model runs produce very high- $\mathrm{HCHO}$ columns for much of the continental interior. The $C_{F M(r I E)}$ simulated distributions shown in Figure 9 are more similar to those observed by SCIAMACHY, except that they are much higher in both the wet-to-dry transitional period and in the dry season, and contain very high $\mathrm{HCHO}$ columns over Brazilian border with Peru and Bolivia (i.e., where the highest emissions occur as shown in Figure 2). The $C_{F M(L P J(C R U))}$, and $C_{F M(L P J(G C))}$ simulations have a low 

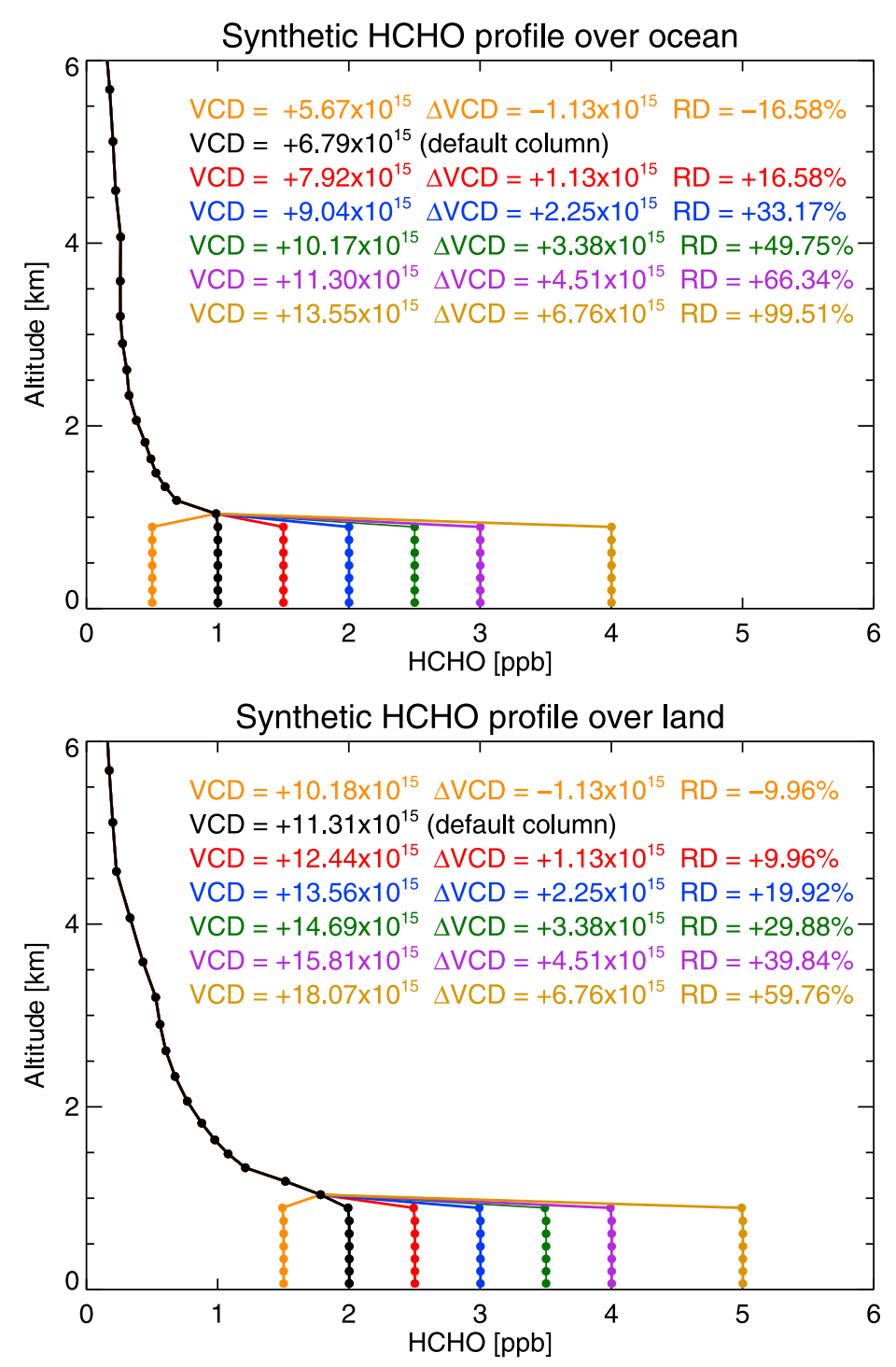

Figure 8. Influence of simulated HCHO near-surface mixing ratios on the corresponding VCD (in molecule $\mathrm{cm}^{-2}$ ). The default model profile (black line) is representative of the HCHO vertical distribution over the (top) ocean and (bottom) land. The colored lines represent successive perturbations to the default profile of -0.5 (orange), +0.5 (red), +1.0 (blue), +1.5 (green), +2.0 (purple), and $+3.0 \mathrm{ppbv}$ (brown) throughout the lowest $1 \mathrm{~km} ; \triangle \mathrm{VCD}$ is the corresponding change in the vertical column due to each perturbation and $\mathrm{RD}$ is the relative difference.

annual mean bias overall of $15 \%$ and $10 \%$, respectively. However, as shown in Figure 11 most of this bias originates from during the wet-to-dry transitional period when isoprene emissions are particularly uncertain [Barkley et al., 2009]. The spatial distributions from these two scenarios are different to the MEGAN-based simulations, but have better correlations in earlier and latter parts of the year as shown in Figure 11. Therefore despite some significant differences, e.g., the evident disagreement in southeastern Brazil during May, the HCHO column distributions based on the LPJGUESS emissions generally give better agreement to the SCIAMACHY data than those based on MEGAN.

[56] Unlike SCIAMACHY, OMI only observes very high HCHO columns deep within the central regions during August-September and has smaller annual mean (about $15 \%$ less relative to SCIAMACHY). Subsequently the positive model bias relative to the OMI observations, is notably higher than with the SCIAMACHY data. Although the simulations using the Caltech chemistry once more have a lower model bias than simulations using the standard mechanism, the bias is still substantial ranging from about 20-100\%. Again, the $C_{F M(r I E)}, C_{F M(L P J(C R U))}$, and $C_{F M(L P J(G C))}$ and $C_{F M(r I E, O H)}$ simulations perform best and have the lowest bias. That said, the spatial correlation is particularly poor in some months, e.g., during May and June for the $C_{F M(L P J(C R U))}$ simulation. Furthermore, all model runs demonstrate a strong seasonality regarding spatial agreement to the OMI observations, as the correlation is highest during July-October and lowest in April. Overall, the $C_{F M(L P J(G C))}$ simulation performs best. However, an extra simulation in which the isoprene emission within the $C_{F M}$ scenario were reduced by $50 \%$ 


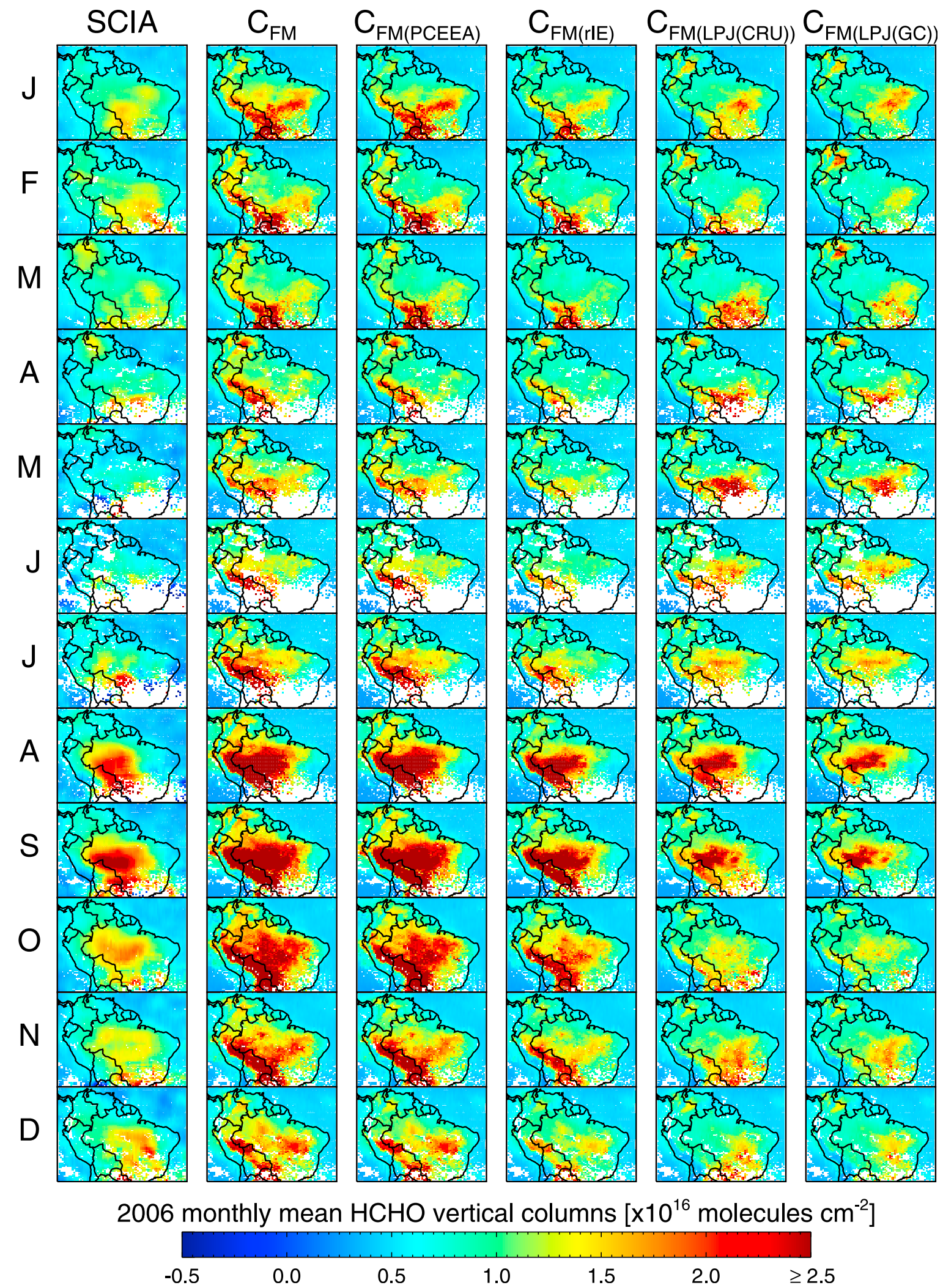

Figure 9. Monthly mean HCHO columns for 2006, corresponding to 09:00-11:00 LT, as observed by SCIAMACHY and simulated by GEOS-Chem using the Caltech chemical mechanism (see Table 5). The SCIAMACHY data have been averaged onto the nested $0.667^{\circ} \times 0.5^{\circ}$ grid using observations with cloud cover $\leq 40 \%$ and smoothed with a $9 \times 9$ box filter to remove noise. The model data have been sampled at the same times and locations as the SCIAMACHY observations but are not smoothed. White-colored regions correspond to areas with no usable SCIAMACHY data. 


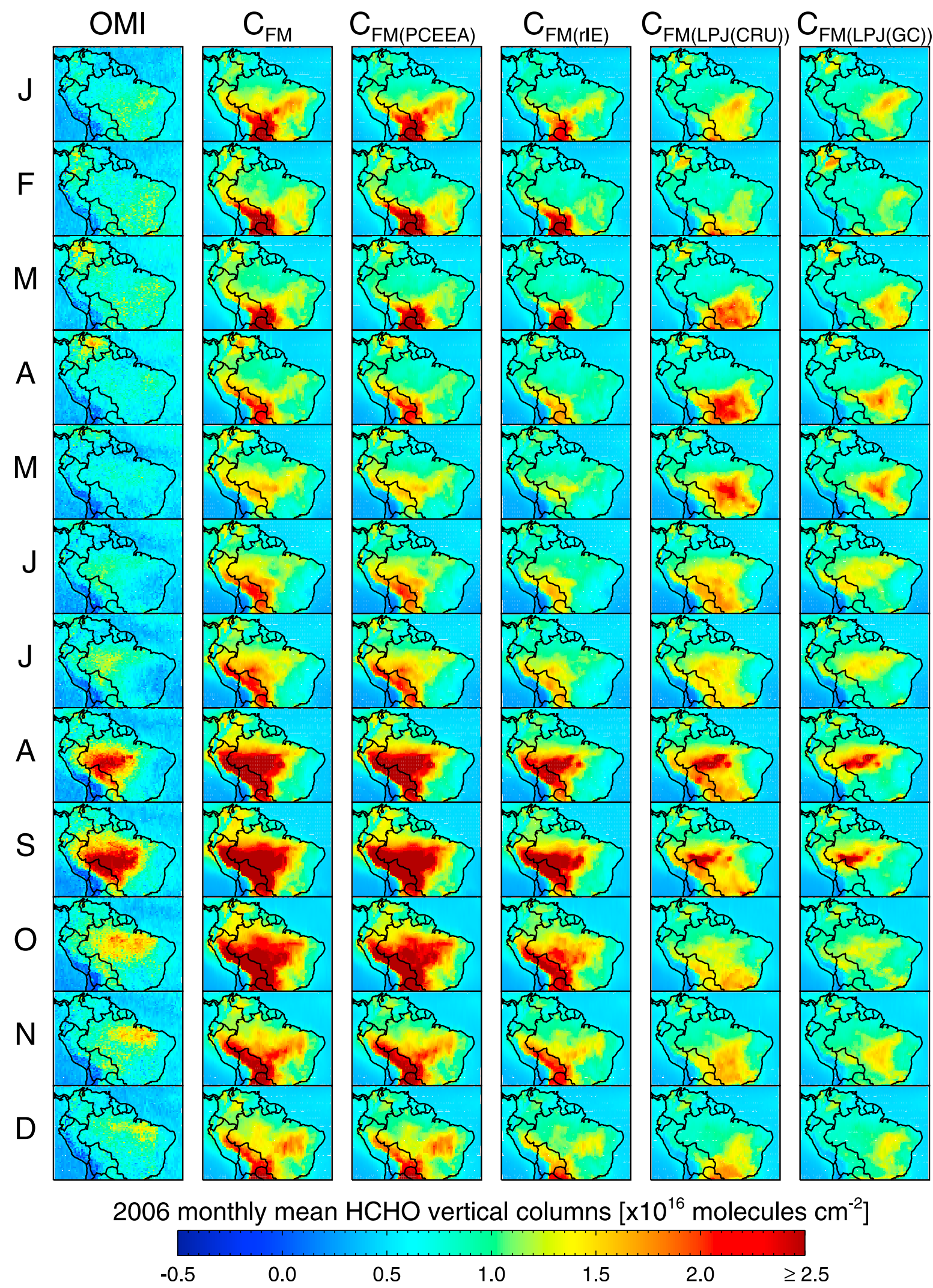

Figure 10. Monthly mean HCHO columns for 2006, corresponding to 12:00-15:00 LT, as observed by OMI and simulated by GEOS-Chem using the Caltech chemical mechanism (see Table 5). The OMI data have been averaged onto the nested $0.667^{\circ} \times 0.5^{\circ}$ grid using observations with cloud cover $\leq 40 \%$. The model data have been sampled at the same times and locations as the OMI observations. Neither the OMI nor the GEOS-Chem data are smoothed. 


\section{SCIAMACHY vs. Geos-Chem}
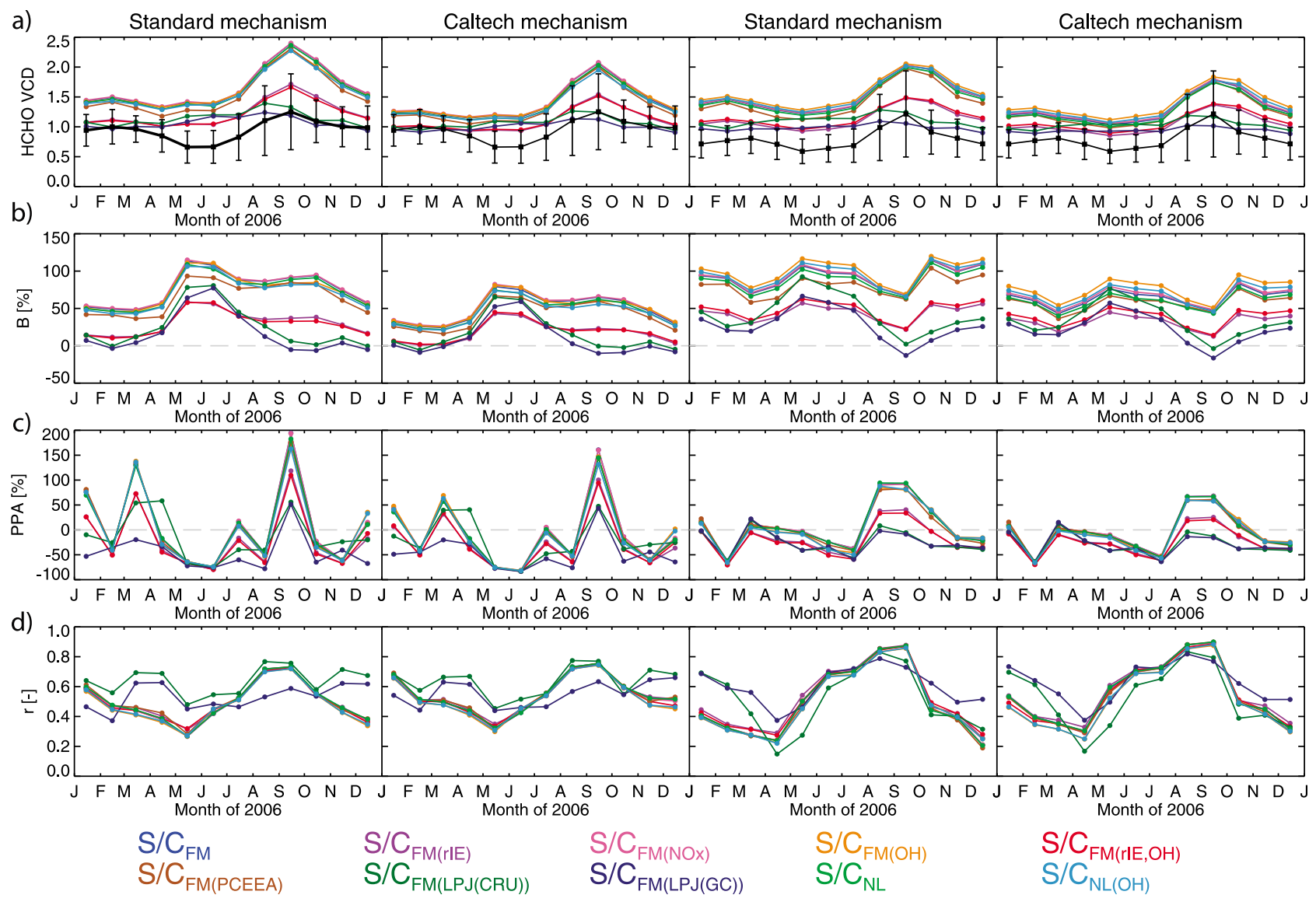

Figure 11. Time series of the monthly mean HCHO column statistics for 2006. (left) Comparison of SCIAMACHY and GEOS-Chem HCHO columns computed with standard and Caltech chemical mechanism. (right) Comparison of OMI HCHO with the model data. Both the SCIAMACHY and OMI data have been averaged onto the nested $0.667^{\circ} \times 0.5^{\circ}$ grid using observations with cloud cover $\leq 40 \%$; the SCIAMACHY data are smoothed with a $9 \times 9$ box filter to remove noise. The model data have been sampled at the same times and locations as the respective satellite observations but are not smoothed. (a) The monthly mean HCHO column (in molecule $\mathrm{cm}^{-2}$ ) with the observations and their \pm 1 standard deviation error bars (plotted in black), (b) the normalized mean bias (\%), (c) the paired peak accuracy (\%), and (d) the correlation are shown. The model simulations are represented by the solid color lines (see Table 5).

improves the agreement to the satellite observations reducing the annual mean bias with respect to SCIAMACHY and OMI to $6 \%$ and $20 \%$, respectively.

[57] We find the influence of boundary layer mixing, soil $\mathrm{NO}_{\mathrm{x}}$ emissions, and $\mathrm{OH}$ recycling on the simulated $\mathrm{HCHO}$ columns to be minor (Figure 11). Use of nonlocal boundary layer mixing reduces the annual bias by about $4 \%$, whilst increased soil $\mathrm{NO}_{\mathrm{x}}$ emissions only slightly increase the bias. Use of $\mathrm{OH}$ recycling worsens the bias by about $10 \%$ when the model is compared with OMI data, and has a minimal effect when it is compared with SCIAMACHY data. This reinforces our earlier findings that the model HCHO columns are predominantly controlled by isoprene emissions and the choice of chemical mechanism. However, in the real atmosphere all these processes occur simultaneously and cannot be decoupled as done in the model (by operator splitting). For example, the influence of boundary layer mixing on the HCHO columns in reality may actually be substantial.
[58] Finally, the burning of tropical vegetation can release significant amounts of HCHO into the atmosphere [Stavrakou et al., 2009a; Yokelson et al., 2008]. To determine the influence biomass burning on the model HCHO columns, we conducted a simulation in which the biomass burning emissions within the $C_{F M}$ scenario were switched off. We find only a small improvement (a reduction of about 5\%) in the annual biases with respect to both the SCIAMACHY and OMI observations. Despite this relatively small impact on the $\mathrm{HCHO}$ columns for the region as a whole, emissions from biomass burning still represent a large source of uncertainty and may partially explain some of the discrepancy between the model and satellite data.

\section{Discussion}

[59] Having evaluated GEOS-Chem against the in situ and satellite observations we find the model has difficulty in 
Table 7. Annual Model HCHO Column Statistics Over Land for 2006

\begin{tabular}{|c|c|c|c|c|c|c|c|c|}
\hline \multirow[b]{2}{*}{ Scenario } & \multicolumn{2}{|c|}{ Mean HCHO VCD ${ }^{a}$} & \multicolumn{2}{|c|}{ Mean B (\%) } & \multicolumn{2}{|c|}{ Mean PPA (\%) } & \multicolumn{2}{|c|}{ Mean $r$} \\
\hline & Standard & Caltech & Standard & Caltech & Standard & Caltech & Standard & Caltech \\
\hline SCIAMACHY & $0.94^{\mathrm{b}}$ & & & & & & & \\
\hline$F M$ & 1.66 & 1.40 & 76 & 49 & 9 & -8 & 0.49 & 0.55 \\
\hline$N L$ & 1.62 & 1.37 & 73 & 46 & 7 & -11 & 0.50 & 0.55 \\
\hline$F M(O H)$ & 1.63 & 1.40 & 74 & 50 & 7 & -8 & 0.48 & 0.53 \\
\hline$N L(O H)$ & 1.59 & 1.35 & 70 & 44 & 5 & -12 & 0.48 & 0.53 \\
\hline$F M(N O x)$ & 1.67 & 1.42 & 78 & 51 & 9 & -7 & 0.49 & 0.54 \\
\hline$F M(P C E E A)$ & 1.55 & 1.33 & 64 & 41 & 6 & -12 & 0.51 & 0.55 \\
\hline$F M(r I E)$ & 1.22 & 1.10 & 31 & 18 & -19 & -28 & 0.50 & 0.55 \\
\hline$F M(r I E, O H)$ & 1.21 & 1.11 & 29 & 18 & -20 & -28 & 0.49 & 0.54 \\
\hline$F M(L P J(C R U))$ & 1.14 & 1.06 & 25 & 16 & -14 & -22 & 0.64 & 0.63 \\
\hline$F M(L P J(G C))$ & 1.07 & 1.00 & 17 & 10 & -46 & -47 & 0.53 & 0.55 \\
\hline OMI & $0.80^{\mathrm{b}}$ & & & & & & & \\
\hline$F M$ & 1.51 & 1.30 & 92 & 64 & 7 & -4 & 0.49 & 0.55 \\
\hline$N L$ & 1.48 & 1.26 & 88 & 60 & 6 & -6 & 0.49 & 0.55 \\
\hline$F M(O H)$ & 1.57 & 1.38 & 100 & 75 & 3 & -6 & 0.48 & 0.52 \\
\hline$N L(O H)$ & 1.54 & 1.33 & 95 & 69 & 2 & -9 & 0.48 & 0.52 \\
\hline$F M(N O x)$ & 1.52 & 1.31 & 93 & 66 & 7 & -4 & 0.49 & 0.55 \\
\hline$F M(P C E E A)$ & 1.43 & 1.25 & 80 & 57 & 3 & -7 & 0.49 & 0.55 \\
\hline$F M(r I E)$ & 1.13 & 1.04 & 44 & 32 & -18 & -24 & 0.52 & 0.57 \\
\hline$F M(r I E, O H)$ & 1.16 & 1.08 & 48 & 38 & -21 & -25 & 0.51 & 0.55 \\
\hline$F M(L P J(C R U))$ & 1.10 & 1.04 & 43 & 34 & -25 & -30 & 0.51 & 0.52 \\
\hline$F M(L P J(G C))$ & 0.99 & 0.94 & 28 & 22 & -25 & -30 & 0.60 & 0.62 \\
\hline
\end{tabular}

${ }^{\mathrm{a}} \mathrm{HCHO}$ vertical column density in units of $\times 10^{16}$ molecules $\mathrm{cm}^{-2}$.

${ }^{\mathrm{b}}$ Mean observation retrieved by each instrument.

reproducing observed isoprene-related chemistry and $\mathrm{HCHO}$ columns over the Amazon Basin. In this section we discuss the potential reasons for this.

[60] We acknowledge that the bottom-up isoprene emissions are a large source of uncertainty. Both the MEGAN and LPJ-GUESS inventories suffer from a lack of constraining measurements, and only extensive field campaigns to catalogue the emissions from tropical plant species will address this problem. Despite the challenges of making measurements within the remote rainforest, campaigns need to target regions of high uncertainty, e.g., Brazilian-Peruvian border, and not locations simply because of logistical ease or existing infrastructure. Moreover, continuous measurements are required to quantify and understand the seasonal variability of isoprene emissions and their response to environmental and phenological changes [Barkley et al., 2009]. However, through using different variants of MEGAN and LPJ-GUESS models we have at least provided a range of estimates, i.e., about $70-170 \mathrm{Tg} \mathrm{a}^{-1}$ over the time period 2005-2008. Of the two emission inventories which it is difficult to say which is better, the LPJ-GUESS estimates give slightly better agreement to the satellite data, but when the basal emission rates are known or measured, as for example at the TROFFEE site (Figure 4), then MEGAN reproduces the observed emissions with a modest bias (see Table 6). On the other hand, aircraft measurements of the above-canopy isoprene fluxes surrounding the TROFFEE site indicated that MEGAN underestimated the emissions from this region [Karl et al., 2007], thus implying that LPJ-GUESS estimates would potentially be much lower than the observations. Similarly, down scaling the MEGAN emissions slightly improves the agreement to satellite $\mathrm{HCHO}$ data, if not the in situ observations; i.e., lower emissions potentially compensate for errors in the chemical mechanism. Despite the different approaches of MEGAN and LPJ-GUESS, in this work they are both forced with meteorological fields from the same GEOS-5 assimilation system, except for the LPJ $(C R U)$ based estimates. Therefore, differences between the two models are entirely due to the driving algorithms and assignment of isoprene emission capacities; both inventories have advantages and disadvantages [see, e.g., Niinemets et al., 2010a, 2010b, and related online discussion].

[61] However, the choice of driving variables is clearly important. This is apparent from the fact that MOHYCAN estimates, which use ECMWF meteorological fields, are about $70 \mathrm{Tg} \mathrm{C} \mathrm{yr}^{-1}$ less than GEOS-Chem's MEGAN estimates, even though they are based on the same emission factors. Although the MOHYCAN model includes the effects of soil moisture, this extra activity term is unlikely to account for all the observed differences; over the Amazon soil moisture term is about 0.7-0.9 [see Müller et al., 2008, Figure 2], i.e., a reduction of only $10-30 \%$ in the isoprene emissions at most. A key question therefore is accuracy of the GEOS-5 meteorological data. To assess the impact of meteorological data on the HCHO columns, we performed two extra sensitivity simulations based on the $S_{F M}$ scenario, during which the $2 \mathrm{~m}$ air temperature (T2m) and PAR (diffuse and direct) were separately increased by $2 \mathrm{~K}$ and $10 \%$, respectively. Owing to these perturbations the isoprene emissions increased from $154 \mathrm{Tg} \mathrm{C}$ to $198 \mathrm{Tg} \mathrm{C}$ and $176 \mathrm{Tg} \mathrm{C}$, respectively. Whilst the increase in PAR increases the HCHO column bias by about $6-7 \%$, the effect of temperature is more substantial increasing the bias by about an extra $25 \%$. The impacts of these changes are nonlinear and difficult to extrapolate, but they at least demonstrate the sensitivity of MEGAN to the input meteorological data, and more importantly that any small bias in temperature will have a notable effect on the simulated HCHO columns.

[62] The failure of GEOS-Chem to simulate observed key species, coupled with its likely excessive production of $\mathrm{HCHO}$, indicate potential inadequacies within the model's chemical mechanism. Given that extensive lumping of 
oxidation intermediates occurs with the mechanism, some degree of uncertainty is expected; intercomparisons of other lumped CTM chemical mechanisms have shown considerable differences in their simulation of isoprene chemistry [e.g., Emmerson and Evans, 2009; Archibald et al., 2010a]. That said, by midafternoon prior to the overpass of OMI, the GEOS-Chem yields are only within 3\% of MCM yields. As GEOS-Chem consistently underestimates $\mathrm{OH}$ concentrations, it is therefore more likely that either $\mathrm{OH}$ is not being generated or recycled fast enough, coupled with the fact that the model isoprene emissions are simply much too high. If observed $\mathrm{OH}$ levels were accurately reproduced by the model it might help reconcile some of the differences to the in situ measurements and satellite $\mathrm{HCHO}$ data. Recently, three pathways for $\mathrm{OH}$ regeneration coupled to the photo-oxidation of isoprene have been proposed: (1) artificial $\mathrm{OH}$ recycling [Lelieveld et al., 2008], (2) $\mathrm{OH}$ regeneration from the production of epoxides [Paulot et al., 2009a], and (3) a radically new theoretical scheme called the Leuven Isoprene Mechanism (LIM0) [Peeters et al., 2009; Peeters and Müller, 2010] We have tested (1) and (2) within this work and found neither to sustain observed $\mathrm{OH}$ levels. We acknowledge that for $\mathrm{OH}$ recycling, an alternative value of $n$ within reaction $\mathrm{R} 1$, or including $\mathrm{OH}$ formation via second generation peroxy radicals, with equivalent reduction in the ISOP $+\mathrm{OH}$ reaction might satisfy the Amazon conditions [e.g., Butler et al., 2008]. However, as we have only one observational campaign to evaluate $n$, setting such values is arbitrary. In any case, the impact of $\mathrm{OH}$ recycling on the simulated HCHO columns is small, as also found in the study of Stavrakou et al. [2009a]. Similarly, epoxide formation as implemented in the Caltech scheme does also not simulate observed $\mathrm{OH}$ levels, and compared with $\mathrm{OH}$ recycling yields only a modest increase in $\mathrm{OH}$. Studies by Archibald et al. [2010b] and Stavrakou et al. [2010] also found only moderate increases in $\mathrm{OH}$ levels produced via $\mathrm{OH}$ recycling and epoxide formation. Nevertheless, the modifications to GEOS-Chem's chemical scheme by Paulot et al. [2009a, $2009 \mathrm{~b}$ ] result in a much improved simulation of the $\mathrm{HCHO}$ columns, probably from improved characterization of organic nitrates [Paulot et al., 2009b], despite remaining uncertainties in their yields and atmospheric fates [Perring et al., 2009; Lockwood et al., 2010].

[63] The LIM0 scheme has demonstrated that it has the potential to generate the very high $\mathrm{OH}$ levels over tropical rainforests [Stavrakou et al., 2010]. The basis of this mechanism is that the isomerization reactions of specific isoprene peroxy radicals, outcompete traditional reactions with $\mathrm{NO}$ and $\mathrm{HO}_{2}$, resulting in the formation of $\mathrm{HO}_{\mathrm{x}}$ radicals and hydroperoxy aldehydes (HPALDs). These HPALDs can easily undergo photolysis and lead to additional production of $\mathrm{OH}$ and also $\mathrm{HCHO}$. Despite some minor refinement to the scheme [Peeters and Müller, 2010], owing to issues raised by the studies of Karl et al. [2009], Paulot et al. [2009a], and Archibald et al. [2010b], the LIM0 mechanisms potentially represents the best option for realistic simulation of the Amazonian atmosphere, though it sill needs extensive evaluation. For example, the low- $\mathrm{NO}_{\mathrm{x}} \mathrm{HCHO}$ yields are largely unknown owing to uncertainties in the isomerization reaction rates and HPALD photolysis products; the formation of HPALDs also partially suppress MVK and MACR production.
[64] The simulations performed at the TROFFEE location (section 4.1) show a pronounced nighttime buildup of isoprene and other oxygenated compounds. Clearly, this phenomena originates from the close diurnal chemical and dynamical coupling that occurs within the lowest part of the troposphere. Furthermore, the nocturnal accumulation of $\mathrm{HCHO}$ most likely contributes to the very high $\mathrm{HCHO}$ columns simulated by GEOS-Chem. This behavior likely arises because the model cannot generate sufficient $\mathrm{OH}$ concentrations to adequately remove the majority of the isoprene emitted during the day. By the late afternoon/early evening as the boundary layer collapses, a buildup of isoprene (and other compounds) occurs within model layers nearest the surface. During the night isoprene is further oxidized to form HCHO. However, observations have shown that near the surface, isoprene decays away very rapidly during the night with lifetime of $\sim 2 \mathrm{~h}$ [Hurst et al., 2001; Holzinger et al., 2002; Karl et al., 2004]. Likely causes of this loss mechanism include dry deposition [Holzinger et al., 2002], or as postulated by Hurst et al. [2001] $\mathrm{OH}$ oxidation and vertical mixing with isoprene-depleted air from above. Karl et al. [2004] showed that substantial loss of isoprene could occur within the rainforest canopy, and that deposition velocities for isoprene and other oxygenated compounds were much greater than current model predictions. In that study, VOC mixing ratios within the surface layer just above the canopy exhibited a minimum in the early morning owing to venting with VOC depleted canopy air and growth of the morning boundary layer. Ganzeveld et al. [2008] suggested that intermittent nocturnal transport could couple the residual layer with the surface, allowing deposition to remove VOCs and oxygenated products. Such events might reduce the elevated mixing ratios that are simulated in the higher model layers. However, since GEOS-Chem does not explicitly model reactive exchange within the canopy, or vertically resolve the shallow nighttime PBL, it cannot mimic these nocturnal processes. In a simple attempt to mix tracers to the ML depth and allow some nocturnal vertical mixing, we performed a sensitivity simulation in which we adjusted the $S_{F M}$ scenario to allow full mixing to occur to two extra model layers beyond the PBL. This alteration dramatically reduced the biases of isoprene and MVK+MACR with respect to the TROFFEE observations to about $4 \%$ and $35 \%$, respectively; the $\mathrm{HCHO}$ column decreased by about $3 \%$, reducing the bias by $4 \%$. Clearly, in future work we must examine the role of diurnal boundary layer mixing much more closely.

[65] Tracers that escape the PBL are vertically mixed by moist convection and advection. A sensitivity study by Stavrakou et al. [2009a] using the Intermediate Model of Global Evolution of Species (IMAGES) CTM showed modeled HCHO columns were strongly influenced by the convection. Over the Amazon those authors found that a doubling of convective fluxes produced relative changes in the vertical column of up to $-10 \%$ [see, e.g., Stavrakou et al., 2009c, Figure 2]. Similarly, aircraft measurements over Suriname have shown that shallow convective mixing could transport air masses from the boundary layer up to about $4 \mathrm{~km}$ [Warneke et al., 2001]. Although we have not examined the impact of convection in this work, a recent analysis by Liu et al. [2010] using GEOS-Chem and CO data, from the Microwave Limb Sounder (MLS) [Waters et al., 2006] and the Tropospheric Emission Spectrometer (TES) [Beer, 
2006], showed that GEOS-5 convection decays at too low an altitude over the Amazon, and that vertical mixing is potentially not strong enough. If convection is too weak, then not enough $\mathrm{HCHO}$ will be transported from the boundary layer to the free troposphere, where photolysis rates are faster and $\mathrm{OH}$ levels higher, and subsequently its photochemical destruction will be less than expected.

[66] Various studies have highlighted the importance of dry deposition as a major factor that influences isoprene and its subsequent oxidation products [ $\mathrm{Karl}$ et al., 2004; von Kuhlmann et al., 2004; Pugh et al., 2010]. Unfortunately, few studies exist by which to evaluate dry deposition scheme within the model. Karl et al. [2010] found average daytime deposition velocities $\left(\mathrm{v}_{d}\right)$ for MVK+MACR to be 1.6 and $2.4 \mathrm{~cm} \mathrm{~s}^{-1}$ within the tropical rainforests of Costa Rica and the Amazon, respectively. For the GABRIEL campaign, Ganzeveld et al. [2008] computed deposition velocities for MVK and MACR of about $1.0 \mathrm{~cm} \mathrm{~s}^{-1}$ during the day, and $0.1 \mathrm{~cm} \mathrm{~s}^{-1}$ at night. From the $S_{F M}$ simulation performed for the TROFFEE comparison, we find similar average day and nighttime values for MVK (and MACR) of 0.8 and $0.1 \mathrm{~cm} \mathrm{~s}^{-1}$, respectively; whilst for PAN we calculate $\mathrm{a}_{d(\text { Day })}=0.7 \mathrm{~cm} \mathrm{~s}^{-1}$, which is consistent with the study of Turnipseed et al. [2006]. However, recent work by Karl et al. [2010], based on plant exposure and wounding experiments, implies plants can adjust their metabolism according to their environmental conditions, and decrease their mesophyllic resistance to deposition. Their incorporation of these new findings within a global CTM resulted in significant increases in global BVOC deposition fluxes, but more relevantly, also in dramatic changes of MVK and MACR concentrations over the Amazon (relative decreases of about $30-35 \%$, see Figures S12 and S13 of their supporting online material). Such large increases in deposition fluxes have the potential to reduce mixing ratios of isoprene oxidation products and limit $\mathrm{HCHO}$ production.

[67] When the model is compared with the satellite $\mathrm{HCHO}$ data, we also have to consider the uncertainties associated with $\mathrm{HCHO}$ retrievals themselves. Here we briefly draw attention to two issues that are of particular relevance: the satellite overpass times, and the ancillary information used within the air mass factor (AMF) calculation (see auxiliary material). The time difference between the satellite overpasses is important since it affects each instrument's respective sampling, e.g., owing to relative cloud coverage, and because it also reflects potential temporal errors within the model, i.e., the model simulation better at 10:00 LT than at 13:30 LT? The better agreement between GEOS-Chem and SCIAMACHY may partially originate from this time difference. Computation of AMFs requires a priori knowledge of aerosols and cloud properties, surface albedo, and HCHO vertical distribution. This last term is provided by a CTM driven by a specific isoprene emission inventory, in this case MEGAN for both instruments (albeit implemented differently); a somewhat circular process. By implementing the MEGAN and LPJGUESS inventories within GEOS-Chem, we have shown they produce very different $\mathrm{HCHO}$ distributions over the Amazon; AMF calculations based these respective emissions will therefore yield different $\mathrm{HCHO}$ vertical columns. Based on aircraft observations over the United States [Millet et al., 2006; Palmer et al., 2003], the estimated AMF error due to uncertainties in the $\mathrm{HCHO}$ vertical profile is about $10 \%$.
However, to our knowledge no one has yet assessed the spatial and temporal components of this error using model HCHO columns based on two different isoprene emission models. Recomputation of AMFs using our model simulations might help reconcile the differences to the satellite data. We intend to investigate this topic in future work.

\section{Summary and Future Implications}

[68] Top-down isoprene emissions derived from satellite observations of HCHO columns potentially offer information on the seasonal and interannual variability of the emissions from largely inaccessible tropical rainforests. However, their accuracy relies critically on the chosen chemistry transport model used to derive the emission estimates. We have presented an evaluation of a high-resolution GEOS-Chem simulation of tropospheric chemistry over tropical South America, in which we have driven model with two different isoprene emission inventories, MEGAN and LPJ-GUESS. The isoprene emissions simulated by the two models vary considerably and have large differences in their annual totals (up to $100 \mathrm{Tg} \mathrm{C}$ ). Based on our simulations and assuming a global emission strength of $500 \mathrm{Tg} \mathrm{C} \mathrm{a}{ }^{-1}$ [Arneth et al., 2008; Guenther et al., 1995], we find the Amazon contributes anywhere between about $15-35 \%$ of the total global emissions.

[69] Knowing that in the future we want to use GEOSChem to determine top-down isoprene emissions, in this first evaluation of the model we have assessed the model's ability to reproduce isoprene and $\mathrm{HCHO}$ chemistry over this region. To achieve this we have performed a comprehensive set of sensitivity simulations to quantify the impact of BVOC emissions, chemistry, boundary layer mixing, and soil $\mathrm{NO}_{\mathrm{x}}$ emissions on the simulated $\mathrm{HCHO}$ columns. Two different chemical mechanisms have been evaluated within the model, and the effects of $\mathrm{OH}$ recycling also examined.

[70] Validation of the model with in situ surface and aircraft measurements reveals GEOS-Chem has difficulty reproducing several observed chemical species. Simulated $\mathrm{OH}$ concentrations are generally underestimated, either because the isoprene emissions are too high and/or that too little $\mathrm{OH}$ is being generated and recycled. We find that use of the Caltech chemical scheme, which includes $\mathrm{OH}$ production via epoxide formation, or the inclusion of $\mathrm{OH}$ recycling does not fully resolve this problem. In addition, we find the model simulates high levels of isoprene and excessive of production of MVK+MACR and $\mathrm{HCHO}$, which is potentially linked to their nighttime accumulation within the residual layer. Of the two chemical schemes tested, the Caltech scheme usually results in a more accurate simulation, based on the available in situ observations.

[71] In our analysis we find that magnitude of the model $\mathrm{HCHO}$ columns are dominated by the choice of chemical mechanism and bottom-up isoprene emission inventory; boundary layer mixing and soil $\mathrm{NO}_{\mathrm{x}}$ emissions have a minor influence. Generally, GEOS-Chem exhibits a positive bias when the model HCHO columns are compared with observations from SCIAMACHY and OMI. Typically we find better agreement with SCIAMACHY than with OMI, although this may reflect differences in the respective retrieval schemes or be related to each instrument's overpass time. Simulations that use the Caltech chemical mechanism 
and/or lowest isoprene emissions provide the best agreement to the satellite data, since they yield lower-HCHO columns. We find the LPJ-GUESS emissions produce HCHO columns closer in magnitude to the satellite observations, compared to simulations based on MEGAN. However, the lower LPJGUESS emissions may be partially offsetting other model errors.

[72] Despite these issues, GEOS-Chem can still be considered a valid tool for the inversion of $\mathrm{HCHO}$ columns measurements if used with care. As we have shown, the $\mathrm{HCHO}$ column is very sensitive to its vertical distribution within the boundary layer: a 20-30\% model bias can result only from 1 ppbv uncertainty within the lowest $1 \mathrm{~km}$. Given the uncertainty of tropical emissions and chemistry, such errors are easily feasible. Furthermore, inaccuracies of the forcing meteorology can have a significant impact on the agreement between the model the satellite data; a small $2 \mathrm{~K}$ temperature error can worsen the bias by about $25 \%$. Owing to the differences between the two satellite products, and the large variation of the simulated HCHO columns, we suggest that top-down emission for the Amazon region cannot be derived using only one choice of model setup and instrument. Instead we believe an ensemble of top-down estimates is required that utilizes data from both emission inventories and both satellite data sets. Furthermore, the uncertainties of topdown emissions with respect to individual model processes need to be properly quantified.

[73] Ongoing examination of GEOS-Chem is necessary to resolve problematic issues, such as the low levels of $\mathrm{OH}$, or the unusual nighttime chemistry within the residual layer. In a follow up study we will examine the diurnal evolution of chemistry, boundary layer mixing and dry deposition within the Amazon rainforest in much greater detail. However, we stress the need for observational data sets that span the lower troposphere, i.e., that provide day and night measurements of emission fluxes and key species both within and above the canopy, and out into the boundary layer and free troposphere. Whilst we acknowledge the many difficulties and expense of making such measurements, without such data it will be difficult to adequately constrain model simulations of the Amazon. Since CTMs and satellite observations are the only tools to study the reactive exchange of the Amazon Basin as a whole, reducing uncertainties in both approaches by using observations from detailed field campaigns undoubtedly represents a worthwhile investment.

[74] Acknowledgments. The authors would like to thank all members of the GABRIEL Science team for their provision of the aircraft data. We would also like to thank Lee Murray (Harvard University) for his help with the local lightning distribution and Daniel Stone and Mat Evans (University of Leeds) for their help setting up the box model. The GEOS-Chem model is managed at Harvard University with support from the NASA Atmospheric Chemistry Modeling and Analysis Program. This work was supported by the Natural Environment Research Council (NERC research grants NE/G013810/1 and NE/D001471). A.A. and D.H. acknowledge support from the Swedish Research Council Formas.

\section{References}

Andreae, M. O., and P. Merlet (2001), Emission of trace gases and aerosols from biomass burning, Global Biogeochem. Cycles, 15(4), 955-966, doi:10.1029/2000GB001382.

Archibald, A. T., M. E. Jenkin, and D. E. Shallcross (2010a), An isoprene mechanism intercomparison, Atmos. Environ., 44(40), 5356-5364, doi:10.1016/j.atmosenv.2009.09.016.
Archibald, A. T., M. C. Cooke, S. R. Utembe, D. E. Shallcross, R. G. Derwent, and M. E. Jenkin (2010b), Impacts of mechanistic changes on $\mathrm{HO}_{x}$ formation and recycling in the oxidation of isoprene, Atmos. Chem. Phys., 10(17), 8097-8118, doi:10.5194/acp-10-8097-2010.

Arneth, A., et al. (2007a), Process-based estimates of terrestrial ecosystem isoprene emissions: Incorporating the effects of a direct $\mathrm{CO}_{2}$-isoprene interaction, Atmos. Chem. Phys., 7(1), 31-53, doi:10.5194/acp-7-31-2007.

Arneth, A., P. A. Miller, M. Scholze, T. Hickler, G. Schurgers, B. Smith, and I. C. Prentice (2007b), $\mathrm{CO}_{2}$ inhibition of global terrestrial isoprene emissions: Potential implications for atmospheric chemistry, Geophys. Res. Lett., 34, L18813, doi:10.1029/2007GL030615.

Arneth, A., R. K. Monson, G. Schurgers, U. Niinemets, and P. I. Palmer (2008), Why are estimates of global terrestrial isoprene emissions so similar (and why is this not so for monoterpenes)?, Atmos. Chem. Phys., 8(16), 4605-4620, doi:10.5194/acp-8-4605-2008.

Arneth, A., et al. (2010), From biota to chemistry and climate: Towards a comprehensive description of trace gas exchange between the biosphere and atmosphere, Biogeosciences, 7(1), 121-149, doi:10.5194/ bg-7-121-2010.

Bäck, J., P. Hari, H. Hakola, E. Juurola, and M. Kulmala (2005), Dynamics of monoterpene emissions in Pinus sylvestris during early spring, Boreal Environ. Res., 10, 409-424.

Barkley, M. P., P. I. Palmer, U. Kuhn, J. Kesselmeier, K. Chance, T. P. Kurosu, R. V. Martin, D. Helmig, and A. Guenther (2008), Net ecosystem fluxes of isoprene over tropical South America inferred from GOME observations of HCHO columns, J. Geophys. Res., 113, D20304, doi:10.1029/ 2008JD009863.

Barkley, M. P., P. I. Palmer, I. D. Smedt, T. Karl, A. Guenther, and M. V. Roozendael (2009), Regulated large-scale annual shutdown of Amazonian isoprene emissions?, Geophys. Res. Lett., 36, L04803, doi:10.1029/ 2008GL036843.

Beer, R. (2006), TES on the Aura mission: Scientific objectives, measurements, and analysis overview, IEEE Trans. Geosci. Remote Sens., 44(5), 1102-1105, doi:10.1109/tgrs.2005.863716.

Bey, I., et al. (2001), Global modeling of tropospheric chemistry with assimilated meteorology: Model description and evaluation, J. Geophys. Res., 106(D19), 23,073-23,096, doi:10.1029/2001JD000807.

Bovensmann, H., J. P. Burrows, M. Buchwitz, J. Frerick, S. Nöel, V. V. Rozanov, K. V. Chance, and A. Goede (1999), SCIAMACHY: Mission objectives and measurement modes, J. Atmos. Sci., 56(2), 127-150.

Burrows, J. P., et al. (1999), The Global Ozone Monitoring Experiment (GOME): Mission concept and first scientific results, J. Atmos. Sci., 56(2), 151-175.

Butler, T. M., D. Taraborrelli, C. Brühl, H. Fischer, H. Harder, M. Martinez, J. Williams, M. G. Lawrence, and J. Lelieveld (2008), Improved simulation of isoprene oxidation chemistry with the ECHAM5/MESSy chemistry-climate model: Lessons from the GABRIEL airborne field campaign, Atmos. Chem. Phys., 8, 4529-4546.

Chance, K., P. I. Palmer, R. J. D. Spurr, R. V. Martin, T. P. Kurosu, and D. J. Jacob (2000), Satellite observations of formaldehyde over North America from GOME, Geophys. Res. Lett., 27(21), 3461-3464, doi:10.1029/2000GL011857.

Chen, D., Y. Wang, M. B. McElroy, K. He, R. M. Yantosca, and P. Le Sager (2009), Regional CO pollution and export in China simulated by the high-resolution nested-grid GEOS-Chem model, Atmos. Chem. Phys., 9(11), 3825-3839, doi:10.5194/acp-9-3825-2009.

Claeys, M., et al. (2004), Formation of secondary organic aerosols through photooxidation of isoprene, Science, 303(5661), 1173-1176, doi: $10.1126 /$ science. 1092805 .

Collins, W. J., R. G. Derwnet, C. E. Johnson, and D. S. Stevenson (2002), The oxidation of organic compounds in the troposphere and their globalwarming potentials, Clim. Change, 52(4), 453-479, doi:10.1023/ A:1014221225434.

De Smedt, I., J.-F. Müller, T. Stavrakou, R. van der A, H. Eskes, and M. Van Roozendael (2008), Twelve years of global observation of formaldehyde in the troposphere using GOME and SCIAMACHY sensors, Atmos. Chem. Phys., 8, 4947-4963, doi:10.5194/acp-8-4947-2008.

Eerdekens, G., et al. (2009), Flux estimates of isoprene, methanol and acetone from airborne PTR-MS measurements over the tropical rainforest during the GABRIEL 2005 campaign, Atmos. Chem. Phys., 9(13), 4207-4227, doi:10.5194/acp-9-4207-2009.

Emmerson, K. M., and M. J. Evans (2009), Comparison of tropospheric gas-phase chemistry schemes for use within global models, Atmos. Chem. Phys., 9(5), 1831-1845, doi:10.5194/acp-9-1831-2009.

European Space Agency (1995), The GOME users manual, Eur. Space Agency Spec. Publ. SP-1182, edited by F. Bednarz, Paris.

Fiore, A. M., D. J. Jacob, I. Bey, R. M. Yantosca, B. D. Field, and J. G. Wilkinson (2002), Background ozone over the United States in summer: 
Origin and contribution to pollution episodes, J. Geophys. Res., 107 (D15), 4275, doi:10.1029/2001JD000982.

Fiore, A. M., L. W. Horowitz, D. W. Purves, H. Levy II, M. J. Evans, Y. Wang, Q. Li, and R. M. Yantosca (2005), Evaluating the contribution of changes in isoprene emissions to surface ozone trends over the eastern United States, J. Geophys. Res., 110, D12303, doi:10.1029/ 2004JD005485.

Folberth, G., D. A. Hauglustaine, P. Ciais, and J. Lathière (2005), On the role of atmospheric chemistry in the global $\mathrm{CO}_{2}$ budget, Geophys. Res. Lett., 32, L08801, doi:10.1029/2004GL021812.

Fu, T.-M., D. J. Jacob, P. I. Palmer, K. Chance, Y. X. Wang, B. Barletta, D. R. Blake, J. C. Stanton, and M. J. Pilling (2007), Space-based formaldehyde measurements as constraints on volatile organic compound emissions in east and south Asia and implications for ozone, J. Geophys. Res., 112, D06312, doi:10.1029/2006JD007853.

Ganzeveld, L., and J. Lelieveld (2004), Impact of Amazonian deforestation on atmospheric chemistry, Geophys. Res. Lett., 31, L06105, doi:10.1029/ 2003 GL019205.

Ganzeveld, L., J. Lelieveld, F. J. Dentener, M. C. Krol, and G.-J. Roelofs (2002), Atmosphere-biosphere trace gas exchanges simulated with a single-column model, J. Geophys. Res., 107(D16), 4297, doi:10.1029/ 2001JD000684.

Ganzeveld, L., et al. (2008), Surface and boundary layer exchanges of volatile organic compounds, nitrogen oxides and ozone during the GABRIEL campaign, Atmos. Chem. Phys., 8(20), 6223-6243, doi:10.5194/acp-8-6223-2008.

Gebhardt, S., A. Colomb, R. Hofmann, J. Williams, and J. Lelieveld (2008), Halogenated organic species over the tropical South American rainforest, Atmos. Chem. Phys., 8(12), 3185-3197, doi:10.5194/acp-83185-2008.

Granier, C., G. Pétron, J.-F. Müller, and G. Brasseur (2000), The impact of natural and anthropogenic hydrocarbons on the tropospheric budget of carbon monoxide, 34(29-30), 5255-5270, doi:10.1016/S1352-2310(00) 00299-5.

Guenther, A. (2002), The contribution of reactive carbon emissions from vegetation to the carbon balance of terrestrial ecosystems, Chemosphere, 49(8), 837-844.

Guenther, A., and C. Wiedinmyer (2007), User's guide to the Model of Emissions of Gases and Aerosols from Nature (MEGAN), version 2.01, report, Natl. Cent. for Atmos. Res., Boulder, Colo.

Guenther, A., et al. (1995), A global model of natural volatile organic compound emissions, J. Geophys. Res., 100(D5), 8873-8892, doi:10.1029/ 94JD02950.

Guenther, A., B. Baugh, G. Brasseur, J. Greenberg, P. Harley, L. Klinger, D. Serça, and L. Vierling (1999), Isoprene emission estimates and uncertainties for the central African EXPRESSO study domain, J. Geophys. Res., 104(D23), 30,625-30,639.

Guenther, A., T. Karl, P. Harley, C. Wiedinmyer, P. I. Palmer, and C. Geron (2006), Estimates of global terrestrial isoprene emissions using MEGAN (Model of Emissions of Gases and Aerosols from Nature), Atmos. Chem. Phys., 6(11), 3181-3210, doi:10.5194/acp-6-3181-2006.

Helmig, D., et al. (1998), Vertical profiling and determination of landscape fluxes of biogenic non-methane hydrocarbons within the planetary boundary layer in the Peruvian Amazon, J. Geophys. Res., 103(D19), 25,519-25,532, doi:10.1029/98JD01023.

Holtslag, A., and B. Boville (1993), Local versus nonlocal boundary-layer diffusion in a global climate model, J. Clim., 6(10), 1825-1842.

Holzinger, R., E. Sanhueza, R. von Kuhlmann, B. Kleiss, L. Donoso, and P. J. Crutzen (2002), Diurnal cycles and seasonal variation of isoprene and its oxidation products in the tropical savanna atmosphere, Global Biogeochem. Cycles, 16(4), 1074, doi:10.1029/2001GB001421.

Horowitz, L. W., J. Liang, G. M. Gardner, and D. J. Jacob (1998), Export of reactive nitrogen from North America during summertime: Sensitivity to hydrocarbon chemistry, J. Geophys. Res., 103(D11), 13,451-13,476, doi:10.1029/97JD03142.

Hurst, J. M., et al. (2001), Investigation of the nighttime decay of isoprene, J. Geophys. Res., 106(D20), 24,335-24,346, doi:10.1029/ 2000JD900727.

Jenkin, M. E., and K. C. Clemitshaw (2000), Ozone and other secondary photochemical pollutants: Chemical processes governing their formation in the planetary boundary layer, 34(16), 2499-2527, doi:10.1016/S13522310(99)00478-1.

Jenkin, M. E., S. M. Saunders, V. Wagner, and M. J. Pilling (2003), Protocol for the development of the Master Chemical Mechanism, MCM v3 (Part B): Tropospheric degradation of aromatic volatile organic compounds, Atmos. Chem. Phys., 3(1), 181-193, doi:10.5194/acp-3-181-2003.

Jöckel, P., et al. (2006), The atmospheric chemistry general circulation model ECHAM5/MESSy1: Consistent simulation of ozone from the sur- face to the mesosphere, Atmos. Chem. Phys., 6(12), 5067-5104, doi:10.5194/acp-6-5067-2006.

Kanakidou, M., et al. (2005), Organic aerosol and global climate modelling: A review, Atmos. Chem. Phys., 5(4), 1053-1123, doi:10.5194/acp-5-10532005 .

Karl, T., M. Potosnak, A. Guenther, D. Clark, J. Walker, J. D. Herrick, and C. Geron (2004), Exchange processes of volatile organic compounds above a tropical rain forest: Implications for modeling tropospheric chemistry above dense vegetation, J. Geophys. Res., 109, D18306, doi:10.1029/2004JD004738.

Karl, T., A. Guenther, R. J. Yokelson, J. Greenberg, M. Potosnak, D. R. Blake, and P. Artaxo (2007), The tropical forest and fire emissions experiment: Emission, chemistry, and transport of biogenic volatile organic compounds in the lower atmosphere over Amazonia, J. Geophys. Res., 112, D18302, doi:10.1029/2007JD008539.

Karl, T., A. Guenther, A. Turnipseed, G. Tyndall, P. Artaxo, and S. Martin (2009), Rapid formation of isoprene photo-oxidation products observed in Amazonia, Atmos. Chem. Phys., 9(20), 7753-7767, doi:10.5194/acp-97753-2009.

Karl, T., P. Harley, L. Emmons, B. Thornton, A. Guenther, C. Basu, A. Turnipseed, and K. Jardine (2010), Efficient atmospheric cleansing of oxidized organic trace gases by vegetation, Science, 330(6005), 816-819, doi:10.1126/science. 1192534.

Kesselmeier, J., et al. (2002), Volatile organic compound emissions in relation to plant carbon fixation and the terrestrial carbon budget, Global Biogeochem. Cycles, 16(4), 1126, doi:10.1029/2001GB001813.

Krol, M. C., M. J. Molemaker, and J. V. G. de Arellano (2000), Effects of turbulence and heterogeneous emissions on photochemically active species in the convective boundary layer, J. Geophys. Res., 105 (D5), 6871-6884, doi:10.1029/1999JD900958.

Kubistin, D., et al. (2010), Hydroxyl radicals in the tropical troposphere over the Suriname rainforest: Comparison of measurements with the box model MECCA, Atmos. Chem. Phys., 10(19), 9705-9728, doi:10.5194/acp-10-9705-2010.

Kuhn, U., et al. (2002), Isoprene and monoterpene emissions of Amazônian tree species during the wet season: Direct and indirect investigations on controlling environmental functions, J. Geophys. Res., 107(D20), 8071, doi:10.1029/2001JD000978.

Kuhn, U., et al. (2004), Seasonal differences in isoprene and light-dependent monoterpene emission by Amazonian tree species, Global Change Biol., 10(5), 663-682, doi:10.1111/j.1529-8817.2003.00771.x.

Kuhn, U., et al. (2007), Isoprene and monoterpene fluxes from Central Amazonian rainforest inferred from tower-based and airborne measurements, and implications on the atmospheric chemistry and the local carbon budget, Atmos. Chem. Phys., 7(11), 2855-2879, doi:10.5194/acp-7-28552007.

Lelieveld, J., et al. (2008), Atmospheric oxidation capacity sustained by a tropical forest, Nature, 452, 737-740, doi:10.1038/nature06870.

Levelt, P. F., et al. (2006), The Ozone Monitoring Instrument, IEEE Trans. Geosci. Remote Sens., 44(5), 1093-1101, doi:10.1109/TGRS.2006.872333. Lin, J.-T., and M. B. McElroy (2010), Impacts of boundary layer mixing on pollutant vertical profiles in the lower troposphere: Implications to satellite remote sensing, Atmos. Environ., 44, 1726-1739.

Lin, S.-J., and R. B. Rood (1996), Multidimensional flux form semiLangrangian transport schemes, Mon. Weather Rev., 124, 2046-2070.

Liu, H. Y., D. J. Jacob, I. Bey, and R. M. Yantosca (2001), Constraints from $\mathrm{Pb}-210$ and $\mathrm{Be}-7$ on wet deposition and transport in a global three-dimensional chemical tracer model driven by assimilated meteorological fields, J. Geophys. Res., 106(D11), 12,109-12,128.

Liu, J., J. A. Logan, D. B. A. Jones, N. J. Livesey, I. Megretskaia, C. Carouge, and P. Nedelec (2010), Analysis of CO in the tropical troposphere using Aura satellite data and the GEOS-Chem model: Insights into transport characteristics of the GEOS meteorological products, Atmos. Chem. Phys., 10(24), 12,207-12,232, doi:10.5194/acp-10-12207-2010.

Lockwood, A. L., P. B. Shepson, M. N. Fiddler, and M. Alaghmand (2010), Isoprene nitrates: Preparation, separation, identification, yields, and atmospheric chemistry, Atmos. Chem. Phys., 10(13), 6169-6178, doi:10.5194/acp-10-6169-2010.

Mari, C., D. J. Jacob, and P. Bechtold (2000), Transport and scavenging of soluble gases in a deep convective cloud, J. Geophys. Res., 105(D17), 22,255-22,267.

Martinez, M., et al. (2010), Hydroxyl radicals in the tropical troposphere over the Suriname rainforest: Airborne measurements, Atmos. Chem. Phys., 10(8), 3759-3773, doi:10.5194/acp-10-3759-2010.

Millet, D. B., et al. (2006), Formaldehyde distribution over North America: Implications for satellite retrievals of formaldehyde columns and isoprene emission, J. Geophys. Res., 111, D24S02, doi:10.1029/2005JD006853.

Millet, D. B., D. J. Jacob, K. Folkert Boersma, T.-M. Fu, T. P. Kurosu, K. Chance, C. L. Heald, and A. Guenther (2007), Spatial distribution of 
isoprene emissions from North America derived from formaldehyde column measurements by the OMI satellite sensor, J. Geophys. Res. 113, D02307, doi:10.1029/2007JD008950.

Millet, D. B., et al. (2010), Global atmospheric budget of acetaldehyde: 3-D model analysis and constraints from in-situ and satellite observations, Atmos. Chem. Phys., 10(7), 3405-3425, doi:10.5194/acp-10-3405-2010.

Monson, R. K., and E. A. Holland (2001), Bisopheric trace gas fluxes and their control over tropospheric chemsitry, Annu. Rev. Ecol. Syst., 32, 547-576.

Moorthi, S., and M. J. Suarez (1992), Relaxed Arakawa-Schubert: A parameterization of moist convection for general circulation models, Mon. Weather Rev., 120(6), 978-1002.

Müller, J.-F., et al. (2008), Global isoprene emissions estimated using MEGAN, ECMWF analyses and a detailed canopy environment model, Atmos. Chem. Phys., 8(5), 1329-1341, doi:10.5194/acp-8-1329-2008.

Myneni, R. B., et al. (2007), Large seasonal swings in leaf area of Amazon rainforests, Proc. Natl. Acad. Sci., 104(12), 4820-4823, doi:10.1073/ pnas.0611338104.

Niinemets, Ü., J. D. Tenhunen, P. C. Harley, and R. Steinbrecher (1999), A model of isoprene emission based on energetic requirements for isoprene synthesis and leaf photosynthetic properties for Liquidambar and Quercus, Plant Cell Environ., 22(17), 1319-1335, doi:10.1046/j.13653040.1999.00505.x.

Niinemets, Ü., R. K. Monson, A. Arneth, P. Ciccioli, J. Kesselmeier, U. Kuhn, S. M. Noe, J. Penuelas, and M. Staudt (2010a), The leaf-level emission factor of volatile isoprenoids: Caveats, model algorithms, response shapes and scaling, Biogeosciences, 7(6), 1809-1832, doi:10.5194/bg-7-1809-2010.

Niinemets, Ü., A. Arneth, U. Kuhn, R. K. Monson, J. Penuelas, and M. Staudt (2010b), The emission factor of volatile isoprenoids: Stress, acclimation, and developmental responses, Biogeosciences, 7(7), 2203-2223, doi:10.5194/bg-7-2203-2010.

Palmer, P. I., D. J. Jacob, A. M. Fiore, R. V. Martin, K. Chance, and T. P. Kurosu (2003), Mapping isoprene emissions over North America using formaldehyde column observations from space, J. Geophys. Res., 108 (D6), 4180, doi:10.1029/2002JD002153.

Palmer, P. I., et al. (2006), Quantifying the seasonal and interannual variability of North American isoprene emissions using satellite observations of formaldehyde column, J. Geophys. Res., 111, D12315, doi:10.1029/ 2005JD006689.

Park, R. J., D. J. Jacob, B. D. Field, R. M. Yantosca, and M. Chin (2004), Natural and transboundary pollution influences on sulfate-nitrateammonium aerosols in the United States: Implications for policy, $J$. Geophys. Res., 109, D15204, doi:10.1029/2003JD004473.

Paulot, F., J. D. Crounse, H. G. Kjaergaard, A. Kurten, J. M. St. Clair, J. H. Seinfeld, and P. O. Wennberg (2009a), Unexpected epoxide formation in the gas-phase photooxidation of isoprene, Science, 325 (5941), 730-733, doi:10.1126/science.1172910.

Paulot, F., J. D. Crounse, H. G. Kjaergaard, J. H. Kroll, J. H. Seinfeld, and P. O. Wennberg (2009b), Isoprene photooxidation: New insights into the production of acids and organic nitrates, Atmos. Chem. Phys., 9(4), 1479-1501, doi:10.5194/acp-9-1479-2009.

Peeters, J., and J.-F. Müller (2010), $\mathrm{HO}_{x}$ radical regeneration in the isoprene oxidation via peroxy radical isomerisations. Part II: Experimental evidence and global impact, Phys. Chem. Chem. Phys., 12(42), 14,227-14,235, doi:10.1039/c0cp00811g.

Peeters, J., T. L. Nguyen, and L. Vereecken (2009), $\mathrm{HO}_{x}$ radical regeneration in the oxidation of isoprene, Phys. Chem. Chem. Phys., 11(28), 5935-5939, doi:10.1039/b908511d.

Perring, A. E., A. Wisthaler, M. Graus, P. J. Wooldridge, A. L. Lockwood, L. H. Mielke, P. B. Shepson, A. Hansel, and R. C. Cohen (2009), A product study of the isoprene+ $+\mathrm{NO}_{3}$ reaction, Atmos. Chem. Phys., 9(14), 4945-4956, doi:10.5194/acp-9-4945-2009.

Pike, R. C., et al. (2010), $\mathrm{NO}_{x}$ and $\mathrm{O}_{3}$ above a tropical rainforest: An analysis with a global and box model, Atmos. Chem. Phys., 10(21), 10,607-10,620, doi:10.5194/acp-10-10607-2010.

Poisson, N., M. Kanakidou, and P. J. Crutzen (2000), Impact of nonmethane hydrocarbons on tropospheric chemistry and the oxidizing power of the global troposphere: 3-dimensional modelling results, J. Atmos. Chem., 36(2), 157-230, doi:10.1023/A:1006300616544.

Pugh, T. A. M., et al. (2010), Simulating atmospheric composition over a south-east asian tropical rainforest: Performance of a chemistry box model, Atmos. Chem. Phys., 10(1), 279-298, doi:10.5194/acp-10-279-2010.

Rienecker, M., et al. (2008), The GEOS-5 data assimilation systemDocumentation of versions 5.0.1, 5.1.0, and 5.2.0, Tech. Rep. Ser. Global Model. Data Assimilation 27, Global Model. and Assimilation Off., NASA Goddard Space Flight Cent., Greenblet, Md.

Sakulyanontvittaya, T., T. Duhl, C. Wiedinmyer, D. Helmig, S. Matsunaga, M. Potosnak, J. Milford, and A. Guenther (2008), Monoterpene and sesquiterpene emission estimates for the United States, Environ. Sci. Technol., 42(5), 1623-1629, doi:10.1021/es702274e.

Sanderson, M. G., C. D. Jones, W. J. Collins, C. E. Johnson, and R. G. Derwent (2003), Effect of climate change on isoprene emissions and surface ozone levels, Geophys. Res. Lett., 30(18), 1936, doi:10.1029/ 2003GL017642.

Sandu, A., and R. Sander (2006), Technical note: Simulating chemical systems in Fortran 90 and Matlab with the Kinetic PreProcessor KPP-2.1, Atmos. Chem. Phys., 6(1), 187-195, doi:10.5194/acp-6-1872006.

Saunders, S. M., M. E. Jenkin, R. G. Derwent, and M. J. Pilling (2003), Protocol for the development of the Master Chemical Mechanism, MCM v3 (Part A): Tropospheric degradation of non-aromatic volatile organic compounds, Atmos. Chem. Phys., 3(1), 161-180, doi:10.5194/ acp-3-161-2003.

Schurgers, G., A. Arneth, R. Holzinger, and A. H. Goldstein (2009a), Process-based modelling of biogenic monoterpene emissions combining production and release from storage, Atmos. Chem. Phys., 9(10), 3409-3423, doi:10.5194/acp-9-3409-2009.

Schurgers, G., T. Hickler, P. A. Miller, and A. Arneth (2009b), European emissions of isoprene and monoterpenes from the Last Glacial Maximum to present, Biogeosciences, 6(12), 2779-2797, doi:10.5194/bg-6-27792009.

Shim, C., Y. Wang, Y. Choi, P. I. Palmer, D. S. Abbot, and K. Chance (2005), Constraining global isoprene emissions with Global Ozone Monitoring Experiment (GOME) formaldehyde column measurements, J. Geophys. Res., 110, D24301, doi:10.1029/2004JD005629.

Sitch, S., et al. (2003), Evaluation of ecosystem dynamics, plant geography, and terrestrial carbon cycling in the LPJ dynamic global vegetation model, Global Change Biol., 9(2), 161-185, doi:10.1046/j.13652486.2003.00569.x.

Smith, B., I. C. Prentice, and M. T. Sykes (2001), Representation of vegetation dynamics in the modelling of terrestrial ecosystems: Comparing two contrasting approaches within European climate space, Global Ecol. Biogeogr., 10(6), 621-637, doi:10.1046/j.1466-822X.2001. t01-1-00256.x.

Stavrakou, T., J.-F. Müller, I. De Smedt, M. Van Roozendael, G. R. van der Werf, L. Giglio, and A. Guenther (2009a), Evaluating the performance of pyrogenic and biogenic emission inventories against one decade of space-based formaldehyde columns, Atmos. Chem. Phys. 9(3), 1037-1060, doi:10.5194/acp-9-1037-2009.

Stavrakou, T., J.-F. Müller, I. De Smedt, M. Van Roozendael, G. R. van der Werf, L. Giglio, and A. Guenther (2009b), Global emissions of non-methane hydrocarbons deduced from SCIAMACHY formaldehyde columns through 2003-2006, Atmos. Chem. Phys., 9(11), 3663-3679, doi:10.5194/acp-9-3663-2009.

Stavrakou, T., J.-F. Müller, I. De Smedt, M. Van Roozendael, G. R. van der Werf, L. Giglio, and A. Guenther $(2009 \mathrm{c})$, Supplement to "Evaluating the performance of pyrogenic and biogenic emission inventories against one decade of space-based formaldehyde columns", Atmos. Chem. Phys., 9(3), 1037-1060, doi:10.5194/acp-9-1037-2009.

Stavrakou, T., J. Peeters, and J.-F. Müller (2010), Improved global modelling of $\mathrm{HO}_{x}$ recycling in isoprene oxidation: Evaluation against the GABRIEL and INTEX-A aircraft campaign measurements, Atmos. Chem. Phys., 10(20), 9863-9878, doi:10.5194/acp-10-9863-2010.

Stickler, A., et al. (2007), Chemistry, transport and dry deposition of trace gases in the boundary layer over the tropical Atlantic Ocean and the Guyanas during the GABRIEL field campaign, Atmos. Chem. Phys., 7(14), 3933-3956, doi:10.5194/acp-7-3933-2007.

Turnipseed, A. A., et al. (2006), Eddy covariance fluxes of peroxyacetyl nitrates (PANs) and $\mathrm{NO}_{y}$ to a coniferous forest, J. Geophys. Res., 111 D09304, doi:10.1029/2005JD006631.

von Kuhlmann, R., M. G. Lawrence, U. Pöschl, and P. J. Crutzen (2004), Sensitivities in global scale modeling of isoprene, Atmos. Chem. Phys, 4(1), 1-17, doi:10.5194/acp-4-1-2004.

Wang, Y., D. J. Jacob, and J. A. Logan (1998), Global simulation of tropospheric $\mathrm{O}_{3}-\mathrm{NO}_{x}$-hydrocarbon chemistry: 1. Model formulation, J. Geophys. Res., 103, 10,713-10,726, doi:10.1029/98JD00158.

Wang, Y. X., M. B. McElroy, D. J. Jacob, and R. M. Yantosca (2004), A nested grid formulation for chemical transport over Aisa: Applications to CO, J. Geophys. Res., 109, D22307, doi:10.1029/2004JD005237.

Warneke, C., et al. (2001), Isoprene and its oxidation products methyl vinyl ketone, methacrolein, and isoprene related peroxides measured online over the tropical rain forest of Surinam in March 1998, J. Atmos. Chem., $38(2), 167-185$.

Waters, J. W., et al. (2006), The Earth Observing System Microwave Limb Sounder (EOS MLS) on the Aura satellite, IEEE Trans. Geosci. Remote Sens., 44(5), 1075-1092, doi:10.1109/tgrs.2006.873771. 
Wesely, M. L. (1989), Parameterization of surface resistances to gaseous dry deposition in regional scale numerical models, Atmos. Environ. 23(6), 1293-1304.

Wild, O., X. Zhu, and M. J. Prather (2000), Fast-J: Accurate simulation of in- and below-cloud photolysis in tropospheric chemical models, J. Atmos. Chem., 37, 245-282.

Williams, J., N. Yassaa, S. Bartenbach, and J. Lelieveld (2007), Mirror image hydrocarbons from tropical and boreal forests, Atmos. Chem. Phys., 7(3), 973-980, doi:10.5194/acp-7-973-2007.

Yokelson, R. J., T. Karl, P. Artaxo, D. R. Blake, T. J. Christian, D. W. T. Griffith, A. Guenther, and W. M. Hao (2007), The tropical forest and fire emissions experiment: Overview and airborne fire emission factor measurements, Atmos. Chem. Phys., 7(19), 5175-5196, doi:10.5194/acp-75175-2007.

Yokelson, R. J., T. J. Christian, T. G. Karl, and A. Guenther (2008), The tropical forest and fire emissions experiment: Laboratory fire measurements and synthesis of campaign data, Atmos. Chem. Phys., 8(13), 3509-3527, doi:10.5194/acp-8-3509-2008.

Zeng, N., J.-H. Yoon, J. A. Marengo, A. Subramaniam, C. A. Nobre A. Mariotti, and J. D. Neelin (2008), Causes and impacts of the 2005 Amazon drought, Environ. Res. Lett., 3, 014002, doi:10.1088/ $1748-9326 / 3 / 1 / 014002$

A. Arneth and D. Hagberg, Geobiosphere Science Center, Department of Physical Geography and Ecosystems Analysis, Lund University, Sölvegatan 12, Lund SE-223 62, Sweden.
M. P. Barkley, EOS Group, Department of Physics and Astronomy, University of Leicester, University Road, Leicester LE17RH, UK. (mpb14@le.ac.uk)

K. Chance and T. P. Kurosu, Atomic and Molecular Physics Division, Harvard-Smithsonian Center for Astrophysics, 60 Garden St., Cambridge, MA 02138, USA.

D. Chen, Department of Atmospheric and Oceanic Sciences, University of California, 405 Hilgard Ave., Los Angeles, CA 90095-1565, USA.

I. De Smedt, J.-F. Müller, and M. Van Roozendael, Belgian Institute for Space Aeronomy, 3 Ave. Circulaire, Brussels B-1180, Belgium.

L. Ganzeveld, Earth System Sciences, Department of Environmental Sciences, Wageningen University and Research Center, Droevendaalsesteeg 4, Wageningen NL-6708PB, Netherlands.

A. Guenther and T. Karl, National Center of Atmospheric Research, PO Box 3000, Boulder, CO 80307-3000, USA.

J. Mao, Geophysical Fluid Dynamics Laboratory, Princeton University, 201 Forrestal Rd., Princeton, NJ 08628, USA.

P. I. Palmer, School of GeoSciences, University of Edinburgh, King's Buildings, West Mains Road, Edinburgh EH9 3JW, UK.

F. Paulot and P. O. Wennberg, Division of Engineering and Applied Science, California Institute of Technology, 1200 E. California Blvd., Pasadena, CA 91125, USA.

Y. Wang, Ministry of Education Key Laboratory for Earth System Modeling, Center for Earth System Science, Institute for Global Change Studies, Tsinghua University, Weiqing Building, Rm. 602, Beijing 100084, China.

R. M. Yantosca, Division of Engineering and Applied Sciences, Harvard University, 29 Oxford St., Cambridge, MA 02138, USA. 